\title{
Development of Local Circuits in Human Visual Cortex
}

\author{
Andreas Burkhalter, Kerry L. Bernardo, and Vinod Charles \\ Departments of Neurology and Neurological Surgery, and Anatomy and Neurobiology, Washington University School of \\ Medicine, St. Louis, Missouri 63110
}

How we see the world largely depends on the organization of neuronal circuits in visual cortex. Physiological recordings in mammals indicate that circuits develop over a period that extends well into early postnatal ages (LeVay et al., 1980; Albus and Wolf, 1984). Our understanding of how these circuits are assembled during development is still fragmentary (Katz and Callaway, 1992). Here we describe the development of local connections within visual cortex, using the fluorescent dye $1,1^{\prime}$-dioctadecyl-3,3,3',3'-tetramethylindocarbocyanine perchlorate to trace axonal projections in postmortem human brains.

Vertical (intracolumnar) connections between layers $2 / 3$ and 5 , which link neurons representing the same point in the visual field, develop prenatally at 26-29 weeks gestation. In contrast, horizontal (intercolumnar) connections between different points in the visual field develop later. They first emerge prenatally at $\approx 37$ weeks gestation within layers $4 B$ and 5 . After birth ( $>\mathbf{4 0}$ weeks gestation) the fiber density increases rapidly, showing a uniform plexus of connections at 7 weeks postnatal. The more adult-like patchiness of the projection, however, emerges after 8 weeks postnatal. Long-range horizontal connections within layer $2 / 3$ develop after the connections within layers $4 \mathrm{~B}, 5$, and 6 . These connections emerge after 16 weeks postnatal, long after cytochrome oxidase blobs have developed, and reach mature form sometime before 15 months of age. Unlike the patchy horizontal projections within layers $4 \mathrm{~B}$ and 5 , which seem to develop through a process of collateral elimination, long-range projections within layer $2 / 3$ are patchy from the outset and seem to develop with greater topographical precision.

The finding that intracolumnar connections develop before intercolumnar projections suggests that circuits that process local features of a visual scene develop before circuits necessary to integrate these features into a continuous and coherent neural representation of an image. In addition, the sequential development of horizontal connections within layer $4 \mathrm{~B}$ before those within layer $2 / 3$ suggests that circuits that may be related to the processing channel for visual motion develop in advance of those that may be more inti-

\footnotetext{
Received Aug. 3, 1992; revised Oct. 14, 1992; accepted Nov. 10, 1992.

We thank R. R. Johnson and L. Tychsen for helpful comments on the final version of the manuscript. Thanks also to D. D. M. O'Leary, J. M. Nerbonne, S E. Petersen, and T. A. Woolsey, who made valuable contributions to earlier versions of the manuscript. This work was supported by NIH Grant EY05935 to A.B. and the McDonnell Center for Studies of Higher Brain Function.

Correspondence should be addressed to Andreas Burkhalter, Department of Anatomy and Neurobiology 8108, Washington University School of Medicine 660 South Euclid Avenue, St. Louis, MO 63110.

Copyright (C) 1993 Society for Neuroscience 0270-6474/93/131916-16\$05.-00/0
}

mately related to the processing of form, color, and precise stereoscopic depth.

IKey words: human brain, visual cortex, intracortical connections, magnocellular pathway, parvocellular pathway, prenatal development, postnatal development]

Behavioral and electrophysiological testing of visual functions in newborn infants indicates that the human visual system is immature at birth (Atkinson, 1984; Boothe et al., 1985; Van Sluyters et al., 1990). This is likely due to structural immaturities at all levels of the visual pathway, but most especially the visual cortex.

The most direct evidence that the visual cortex in newborn infants is immature derives from the absence of visual functions that are attributed to selective response properties of cortical neurons (Hubel and Wiesel, 1977). Newborns lack binocular vision, and stereoscopic depth perception is not present until 4 months of age (Birch et al., 1982). Similarly, orientation-selective mechanisms are not present at birth and can only be detected after the second postnatal month (Braddick et al., 1986; Atkinson et al., 1989). The same is true for directionally selective mechanisms that do not begin to emerge until 2 months of age (Wattham-Bell, 1991, 1992). It is generally assumed that all of these functions are generated within distinct cortical circuits (Gilbert, 1983), dependent upon inter- and intralaminar connections that develop postnatally.

Support for this notion derives from studies of synaptogenesis in human visual cortex. Synapses begin to form in the cortical plate (CP) at 23 weeks gestation (Molliver et al., 1973), but prenatally synaptic contacts proliferate slowly (Huttenlocher and de Courten, 1987). Postnatally, synaptic density rapidly rises to a peak at 8 months of age. This phase is followed by a prolonged period of synapse elimination until the adult density is reached at about 10 years of age. Thus, the initial phase of postnatal synaptogenesis proceeds in remarkable synchrony with the maturation of cortical functions (Wilson, 1988). However, the exact relationship between synaptogenesis and the emergence of circuits remains unknown.

Although the onset of all basic cortical functions is between the second and fourth postnatal months, some functions develop more rapidly than others: direction selectivity reaches relative maturity at 3 months of age (Wattham-Bell, 1991), whereas stereoacuity does not reach adult levels until 6 months of age or older (Birch et al., 1982). A similarly slow maturation was found for orientation-selective mechanisms, which are relatively immature until 6-8 months of age (Morrone and Burr, 1986). All of these data suggest that different cortical circuits develop at different rates but that 8 months after birth basic circuits are in place. 
The purpose of our study was to determine the organization of local connections at different developmental ages, in order to provide more detailed knowledge of the way in which neuroanatomic connections correlate with infant psychophysics. The motivation for our work was that different stages in the development of vision must correlate with emergence of specific connections, which should be evident as distinct patterns of local axonal projections within striate cortex. Because the neuronal circuits for cortical functions are controversial (Bolz and Gilbert, 1986; Chapman et al., 1991; Grieve and Sillito, 1991; Worgötter and Eysel, 1991), we focused on two basic types of connections: (1) vertical connections between layers that provide for local interactions at a single point of the visuotopic map, and (2) horizontal connections within layers that provide for interactions between distant points of the map. To link structure and function more closely, we were particularly interested in comparing the development of horizontal connections within layers 4B and 2/3. Layer 4B is part of the magnocellular (M) processing stream, which conveys information that is utilized mainly for the analysis of stimulus motion (Schiller et al., 1990; Merigan et al., 1991b). Layer $2 / 3$, on the other hand, is dominated by inputs from the parvocellular $(\mathrm{P})$ processing stream (Nealey and Maunsell, 1991) and might be expected to be more concerned with the analysis of color and form (Schiller et al., 1990; Merigan et al., 1991a). To reveal the formation of connections within these streams, we injected primary visual cortex (V1) in postmortem, aldehyde-fixed human brains, ranging from 24 weeks gestation to 5 years postnatal, using DiI as a label of local axonal connections (Godement et al., 1987; Burkhalter and Bernardo, 1989a).

Preliminary reports on the development of local connections within human visual cortex have been published in abstract form (Burkhalter and Bernardo, 1989b; Burkhalter et al., 1990).

\section{Materials and Methods}

Brains without neurological disease were obtained at autopsy. After aldehyde fixation in $2.6 \%$ phosphate-buffered paraformaldehyde containing $0.1 \mathrm{M}$ lysine- $\mathrm{HCl}, 0.8 \% \mathrm{NaIO}_{4}$, and $0.8 \%$ iodoacetic acid for $24-48 \mathrm{hr}$ at $4^{\circ} \mathrm{C}$, brains were blocked into $\approx 5 \mathrm{~mm}$ slabs with horizontal cuts along the fundus of the calcarine sulcus and coronal cuts posterior to the parieto-occipital sulcus. In poorly myelinated young infant brains in which the stria of Gennari is not readily visible, primary visual cortex (V1) was identified by its characteristic cytoarchitecture. For this purpose, prior to DiI labeling, a section was cut from each block and was subsequently stained with bisbenzimide $(0.001 \%$ in $0.1 \mathrm{M}$ phosphate buffer, $\mathrm{pH}$ 7.4) and viewed under UV fluorescence optics. In fetal brains with underdeveloped cytoarchitecture, sections from each block were stained for choline acetyltransferase (Tago et al., 1986), whose distribution served as a marker of the V1/V2 border (Kostovic and Rakic, 1984). For placing DiI (1,1'-dioctadecyl-3,3,3',3'-tetramethylindocarbocyanine perchlorate; Molecular Probes) injections, counterstained sections were aligned with the parent tissue block and small crystals were inserted with a fine glass needle. Injections were made into gray matter, which was approached parallel to the pial surface. This enabled large injections throughout the thickness of cortex and more restricted injections of deep layers without involvement of upper layers. The tissue was stored in $0.1 \mathrm{M}$ phosphate buffer at $21^{\circ} \mathrm{C}$ for $1-6$ months to allow for the dye to diffuse along axons (Godement et al., 1987; Burkhalter and Bernardo, 1989a). Sections were then cut on a Vibratome at $75 \mu \mathrm{m}$, coverslipped with $0.1 \mathrm{M}$ phosphate buffer, and viewed under a fluorescence microscope equipped with rhodamine optics (excitation filter, 546 $\mathrm{nm}$; barrier filter, $580 \mathrm{~nm}$ ). For visualizing layers and areal borders, sections werc counterstained with bisbenzimide and viewed under UV optics (excitation filter, 330-380 nm; barrier filter, $420 \mathrm{~nm}$ ). Layers were identified in fetuses (24-29 weeks gestation) using Chatel's (1976) scheme for human isocortex. In perinatal and postnatal brains, layers were identified according to the description of Braak (1984). Results were obtained from brains at different gestational ( $\mathrm{G}$, weeks from ovulation) and postnatal $(\mathrm{P})$ ages and in each case from a large number of injections (I): G24 weeks $(n=2, \mathrm{I}=24), \mathrm{G} 26$ weeks $(n=1, \mathrm{I}=5), \mathrm{G} 29$ weeks $(n=1, \mathrm{I}=8), \mathrm{G} 37$ weeks $(n=1, \mathrm{I}=10), \mathrm{G} 40$ weeks $(n=1, \mathrm{I}=5)$, P9 days $(n=1, \mathrm{I}=8), \mathrm{P} 7$ weeks $(n=1, \mathrm{I}=8), \mathrm{P} 4$ months $(n=1, \mathrm{I}=$ $10), \mathrm{P} 15$ months $(n=1, \mathrm{I}=8), \mathrm{P} 2$ years $(n=1, \mathrm{I}=11)$, P5 years $(n$ $=1, \mathrm{I}=6$ ). After DiI-labeled axonal patterns were graphically reconstructed using a camera lucida, or photographed, sections were taken off the slide and stored in phosphate buffer to preserve labeling for further cxamination.

In some cases, at the end of the incubation period for DiI, alternate sections were stained for cytochrome oxidase $(\mathrm{CO})$ activity (Tootell et al., 1988). In a single newborn (1 d postnatal) and a single infant (4 months postnatal), the occipital cortex was flattened (Olavarria and Van Sluyters, 1985) and equilibrated in $30 \%$ sucrose, and frozen sections were stained for $\mathrm{CO}$.

\section{Results}

Vertical connections in 24-week-old fetus

To determine the sequence in which vertical and horizontal connections within striate cortex develop, we examined the projections of neurons in superficial layers. Superficial layers are known to send descending axon collaterals to layer 5 and to make long-ranging lateral projections within layer $2 / 3$ (Gilbert and Wiesel, 1983; Rockland and Lund, 1983; Burkhalter and Bernardo, 1989a). In two 24-week-old fetuses, Dil was placed in superficial parts of the CP (Fig. $1 A, B$ ). In each case, Dil labeled a narrow band of radial glial fibers that provide the pathway for neuronal migration from the ventricular zone (VZ) to what will be the most superficial layers of cortex (Rakic, 1978). In the inner half of the marginal zone (MZ), labeling spread horizontally for a considerable distance. At higher power, it was apparent that this labeling was associated with fibers originating from Cajal-Retzius cells (Fig. 2). Just as in Golgi-stained material (Marin-Padilla and Marin-Padilla, 1982), these cells typically showed two thick horizontal dendrites from which short vertical branches extended toward the pial surface. A single axon exited from the cell body and traveled horizontally in parallel with the dendrites. The bulk of labeling in the $\mathrm{CP}$ was in vertical register with the injection site, and very few fibers and cells were seen beyond the lateral margins of the injection (Fig. 1A). Directly below the injection site, labeling consisted not only of radial glial fibers and migrating neurons (Fig. 2), but also of vertically oriented axons and dendrites that arose from ovoidalshaped neurons that presumably were labeled through the distal tips of apical dendrites (Fig. 1C). Many of these CP neurons gave rise to single descending axons that were always unbranched as they passed through the CP. Typically, these efferent fibers entered the underlying intermediate zone (IZ) at an acute angle. At this developmental stage, the $\mathrm{CP}$ was also innervated by ascending fibers. Some of these inputs were collaterals of retrogradely labeled subplate cells (Fig. $1 D$; Kostovic and Rakic, 1980). Other afferents were labeled in a 26 -week-old fetus after injection of the thalamic radiation, which is easily recognized in the unstained tissue as a relatively opaque band below the IZ (Fig. $3 A$ ). Such injections labeled radial glial fibers and presumed thalamocortical afferents (Fig. 3B). As in Figure 1, the brightest labeling was associated with radial glial fibers. Compared to this prominent bundle, the putative thalamocortical input was less conspicuous. However, the afferents could easily be distinguished from radial glial fibers by their less coordinated trajectories within the IZ. At higher power, many of these input fibers could be followed deep into the CP (Fig. 3C). They often looked varicose, were of small caliber, lacked the lamellate ex- 

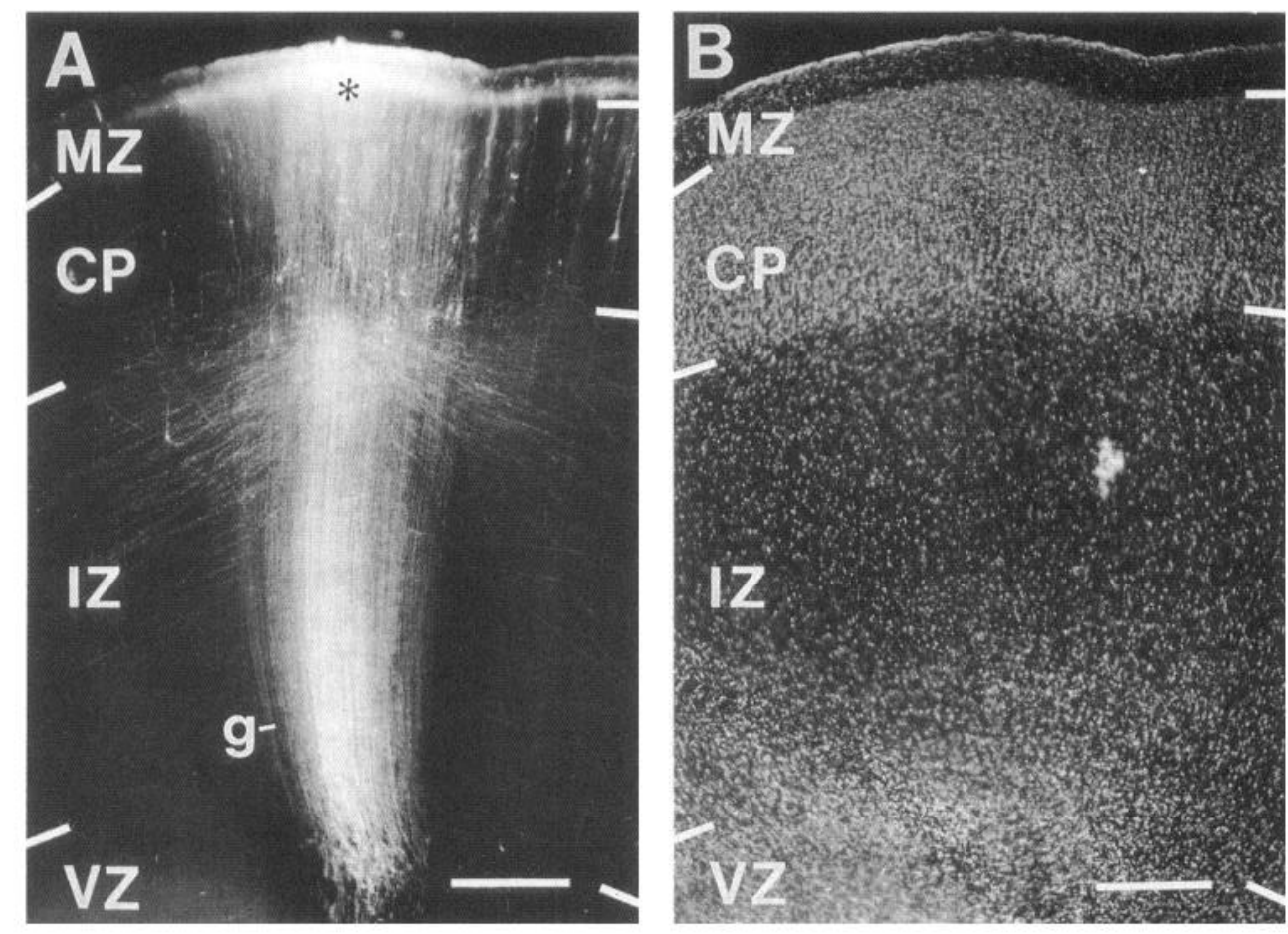

Figure 1. Development of interlaminar connections in human primary visual cortex. $A$, DiI injection (center is marked with asterisk) into superficial half of CP in 24-week-old fetus: fluorescence photomicrograph of coronal section showing band of radial glial fibers $(g)$ extending from VZ to MZ. Cortical input and output axons traverse IZ obliquely. In CP most fibers and cell bodies are immediately below the injection site and horizontal fibers are extremely rare. Labeling in inner half of $\mathrm{MZ}$ on both sides of the injection site represents horizontal fibers. $B$, Section shown in $A$ : fluorescent counterstain with bisbenzimide. CP is not yet differentiated into different layers. $C$, DiIlabeled cell bodies in CP of 24-weekold fetus after superficial CP injection. Section was taken $0.1 \mathrm{~mm}$ from margin of injection site. Descending fibers enter IZ obliquely. $D$, DiI-labeled subplate cells (arrows) in 24-week-old fetus. Center of injection is marked with asterisk. Scale bars, $0.5 \mathrm{~mm}$.
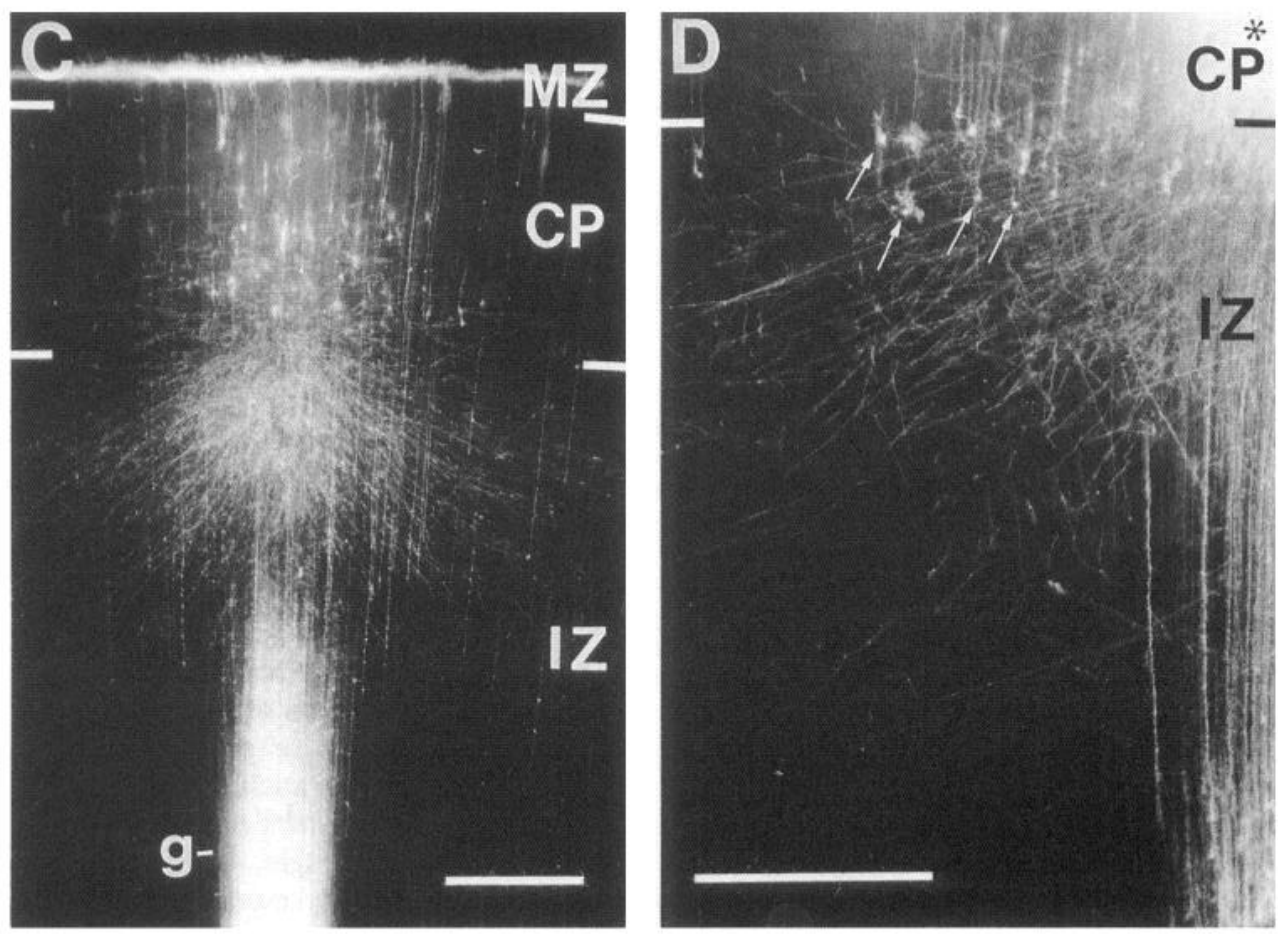

pansions of radial glial fibers (Rakic, 1972), and many terminated in growth cones. Interestingly, these injections never labeled subplate cells. This rules out the possibility that the labeled intracortical fibers represent collaterals of subcortically projecting subplate cells (McConnell et al. 1989) and favors the interpretation that they represent thalamocortical input fibers.

\section{Vertical connections in 29-week-old fetus}

The projection from embryonic layer $2 / 3$ to layer 5 was first evident in a 29 -week-old fetus. At this time the bisbenzimide counterstain revealed the six layers (Fig. $4 B$ ), but provided no evidence for sublaminae within layer 4 . Thus, it was not surprising that bundles of radial glial fibers could still be followed deep into the IZ (Fig. $4 A$ ), suggesting that neuronal migration was still in progress (for review, see Sidman and Rakic, 1973) and thus the cortical lamination pattern is still immature.

Similar to the case shown in Figure 1, the injection site was restricted to the supragranular layers. The vast majority of fibers that emerged from this injection were directed vertically, and few if any horizontal axons were seen in supragranular layers. 


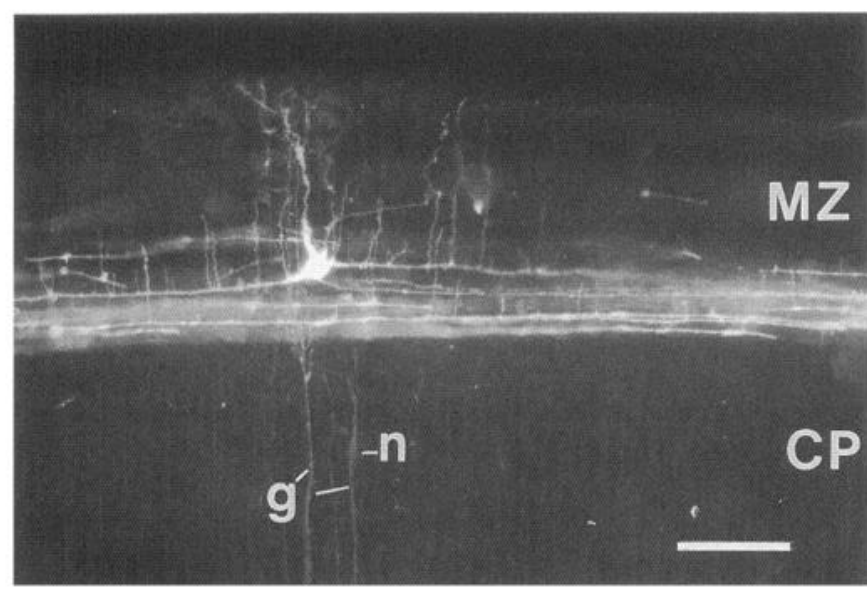

Figure 2. DiI-labeled Cajal-Retzius neuron in inner half of $\mathbf{M Z}$ of primary visual cortex of 24 -week-old human fetus. Radial glial fibers $(g)$ ascend through the $\mathrm{CP}$ and terminate in the inner half of the MZ. Dye transfer from radial glial fibers $(g)$ occasionally gave rise to labeling of migrating neurons $(n)$. Notice that radial glial fiber runs across the weakly labeled neuron. Scale bar, $0.1 \mathrm{~mm}$.

The descending fibers traversed embryonic layer 4 with little branching. By contrast, upon entering layer 5 the fibers produced a dense tangle of short horizontal collaterals that was seen at low power as a prominent band of labeling (Fig. $4 A$ ). This projection zone always contained fibers and cell bodies, suggesting that layers $2 / 3$ and 5 have established reciprocal connections. In marked contrast to the adult cortex (Burkhalter and Bernardo, 1989a), at 29 weeks gestation the band of labeled axon arborizations in embryonic layer 5 was much narrower and had about the same width as the injection site.

\section{Horizontal connections in 24-, 26-, and 29-week-old fetus}

In the adult primate visual cortex, columns in distant parts of the topographic map are linked through long connections in layers $2 / 3,4 B, 5$, and 6 that run parallel to the pial surface (Rockland and Lund, 1983; Livingstone and Hubel, 1984b; Burkhalter and Bernardo, 1989a). To determine the sequence in which these long-range connections develop, DiI injections were made throughout the depth of V1 to label horizontal axon collaterals simultaneously in all layers. At 24 weeks gestation, such cortex-penetrating injections produced labeling patterns (Fig. $5 A, B$ ) that were similar to those seen after injections restricted to superficial parts of the CP (Fig. $1 A$ ): a vertical bundle of radial glial fibers connected the $\mathrm{VZ}$ with the pial surface, horizontal fibers extended only within the $\mathrm{MZ}$, and there were no horizontal fibers within the CP. (Notice that in Fig. $5 A$, the labeling within the $\mathrm{CP}$ on both sides of the injection was not associated specifically with fibers or cell bodies and represents background staining due to local diffusion of DiI.) Well-defined, but short $(<0.5 \mathrm{~mm})$, horizontal fibers within the CP were first seen at 26 weeks gestation. This was in rough synchrony with the beginning of laminar differentiation (Figs. $3 B, 6 B$ ) and the appearance of interlaminar connections (Fig. 4). However, these short horizontal fibers did not emerge simultaneously in every layer. Instead, they appeared at very specific locations: the top of layer 4 and the layer $5 / 6$ border (Fig. $6 A$ ). The presence of retrogradely labeled neurons in layers 4 (Fig. $6 A$ ), 5, and 6 indicated that at least some of the short horizontal fibers may represent local axon collaterals that originated from within the $\mathrm{CP}$. However, because layers 4 and 6 receive thalamocortical afferents (Hubel and Wiesel, 1972) that invade the cortex at about this time (Kostovic and Rakic, 1984), we cannot rule out that some of the fibers may represent thalamocortical afferents.
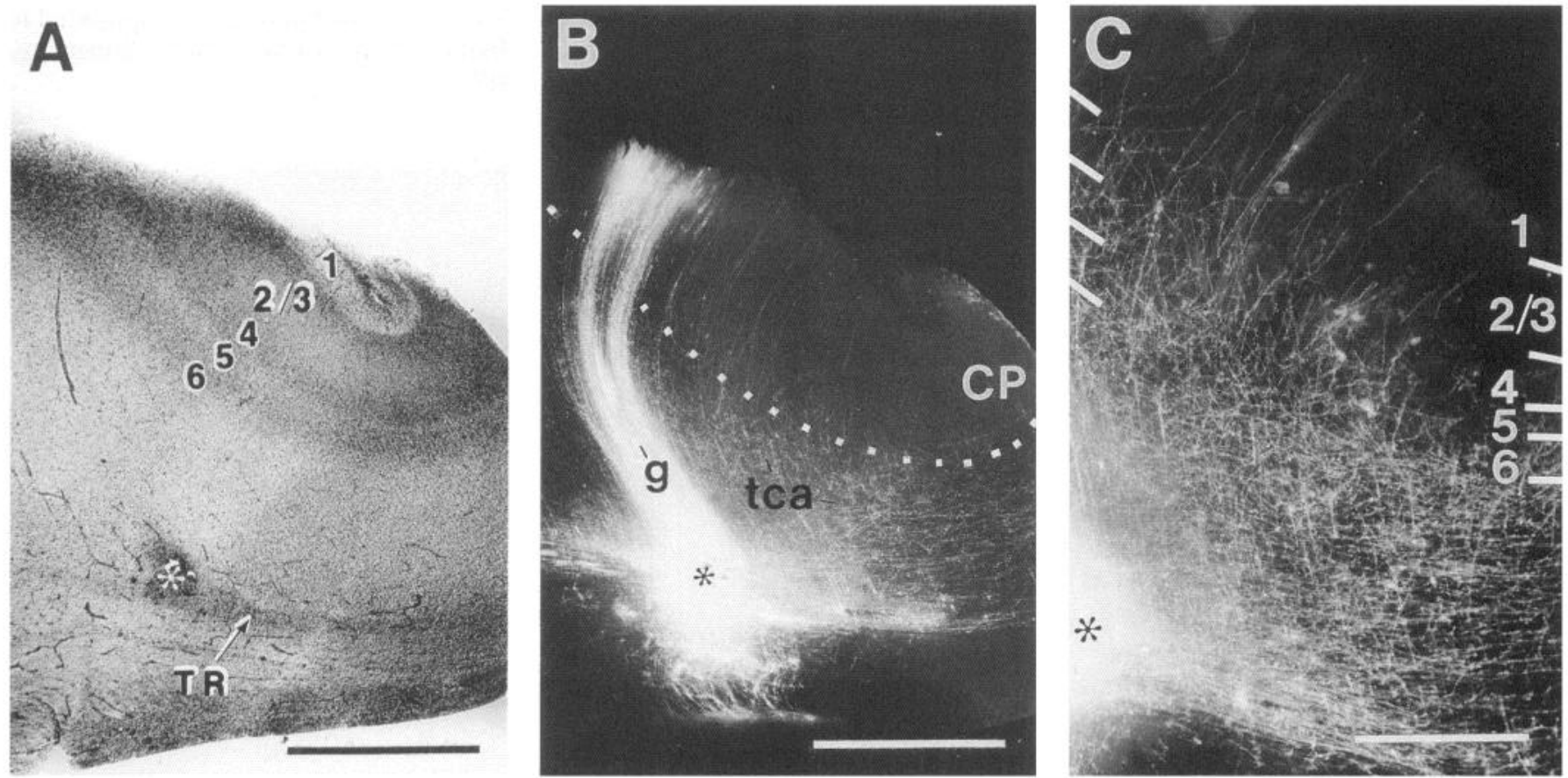

Figure 3. DiI injection into thalamic radiation $(T R)$ below primary visual cortex of 26 -week-old human fetus. $A$, Bright-field photomicrograph of unstained coronal section through calcarine sulcus showing injection site (asterisk) and emerging layers of CP. $B$, Section shown in $A$ viewed under fluorescence illumination. DiI labeled radial glial fibers $(g)$ spanning between VZ and layer 1 . Radially and obliquely oriented putative thalamocortical afferents (tca) enter CP. Center of injection in thalamic radiation is marked with asterisk. $C$, High-power fluorescence photomicrograph of section shown in $B$. Presumed thalamocortical afferents enter all layers of CP. Scale bars: $A$ and $B, 1 \mathrm{~mm} ; C, 0.5 \mathrm{~mm}$. 
Figure 4. A, DiI injection (asterisk) into layer $2 / 3$ of primary visual cortex of 29-week-old human fetus. Labeling to the left of bright spot, representing injection site, is due to DiI diffusion from the injection site after section was cut. Unbranched fibers traverse layer 4. The small-caliber fibers are descending axons of neurons in superficial layers. The larger-caliber fibers represent radial glial processes. Descending axons issue short collaterals in layer 5 , forming a dense plexus of terminal arborization (arrow). Bundle of radial glial fibers $(g)$ traverses IZ. $B$, Section in $A$ counterstained with bisbenzimide, showing emerging cortical layers. Scale bars, $0.5 \mathrm{~mm}$.
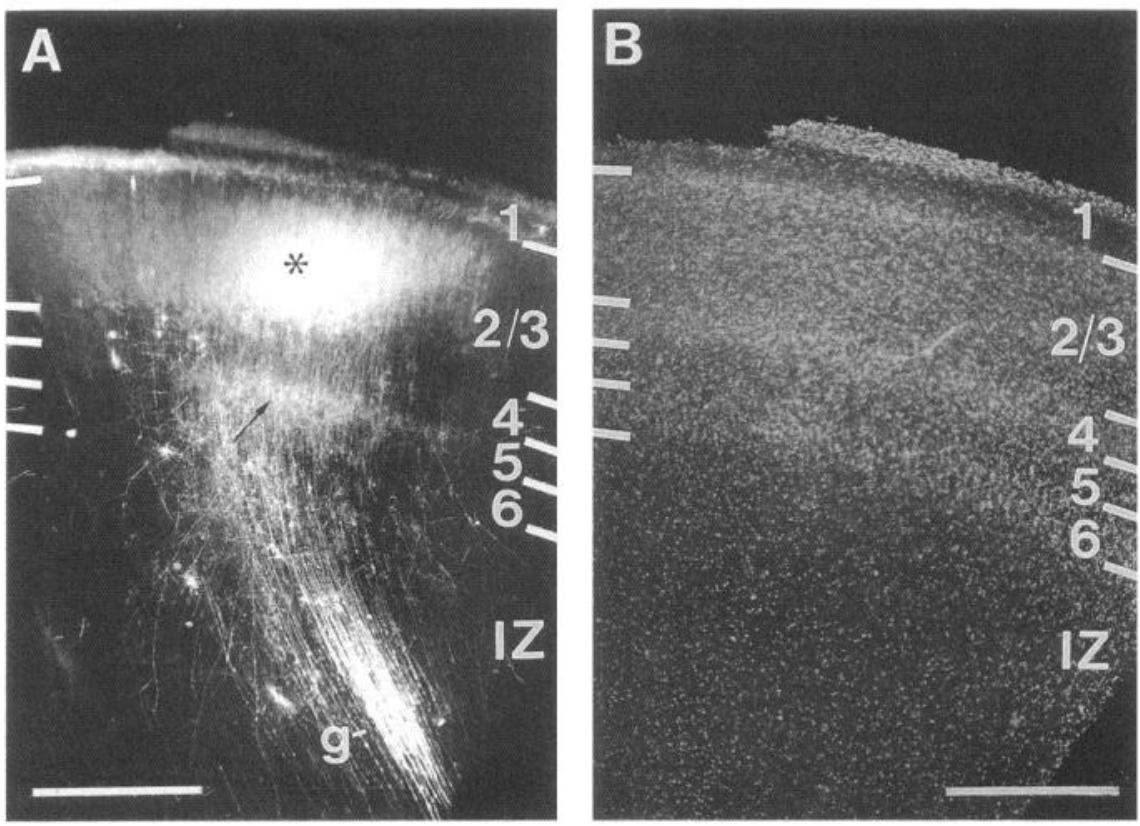

Interestingly, we have never seen horizontal fibers in layer $2 / 3$ in prenatal brains.

\section{Horizontal connections in 37-week-old fetus}

At 37 weeks gestation, shortly before birth, the lateral projections were much longer (up to $2 \mathrm{~mm}$ ) and denser (Fig. 7A). At this age the cortex has matured to a stage where layer 4 showed distinct sublaminae (Fig. $7 B, D$ ), the IZ has become subcortical white matter, and there was no trace of radial glial labeling (Fig. $7 A$ ). Nevertheless, horizontal fibers were still confined mainly to the middle of the CP and the layer $5 / 6$ border. Compared with layer 4 , tangential projections in layer $2 / 3$ were extremely sparse and labeled fibers and cell bodies were rare. At this stage the layers were well differentiated and we are confident that the mid-cortical horizontal fibers occupied layer 4B immediately above the largely unlabeled thalamocortical input layer, $4 \mathrm{C}$. The presence of retrogradely labeled cells within layer 4B indicates that these fibers originated within the cortex. This is further supported by the absence of labeled fibers within layer 4C. In this layer, dense arborizations were only seen when the injection site included white matter and presumably labeled thalamocortical input fibers (Fig. 7C,D). The reason for this preferential labeling of thalamocortical fibers may lie in the profuse branching of thalamocortical afferents within gray matter compared to the fasciculation of unbranched axon trunks within white matter (Blasdel and Lund, 1983).
Figure 5. Development of intralaminar connections in human primary visual cortex. A, Fluorescence photomicrograph of coronal section through $\mathrm{V} 1$. DiI injection (asterisk marks center) through depth of CP in 24-week-old fetus. Weak labeling on both sides of injection represents dye diffusion from the injection site after section was cut. IZ is traversed by bundle of radial glial fibers $(g)$ and obliquely running axons (arrows). No horizontal fibers are seen in CP. $B$, Section shown in $A$ counterstained with bisbenzimide. Scale bars, $0.5 \mathrm{~mm}$.
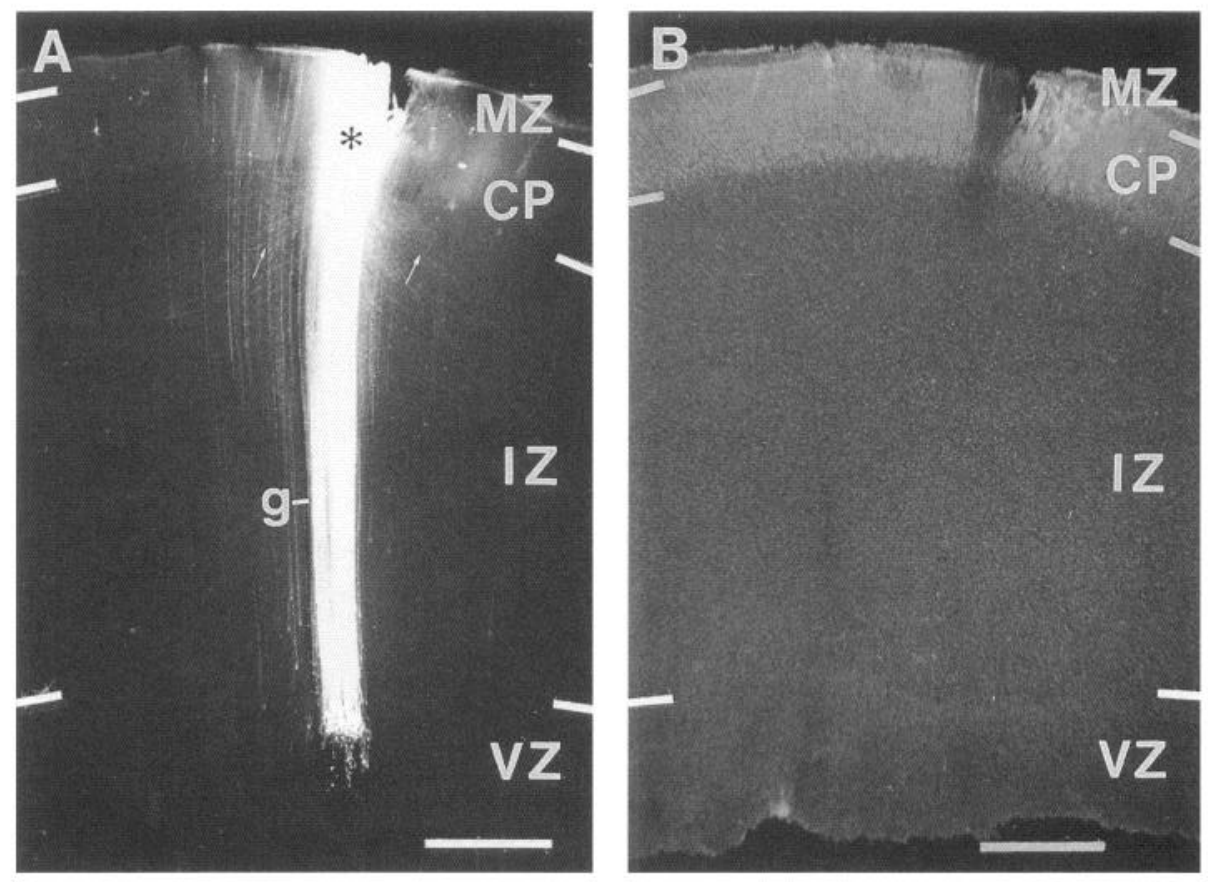

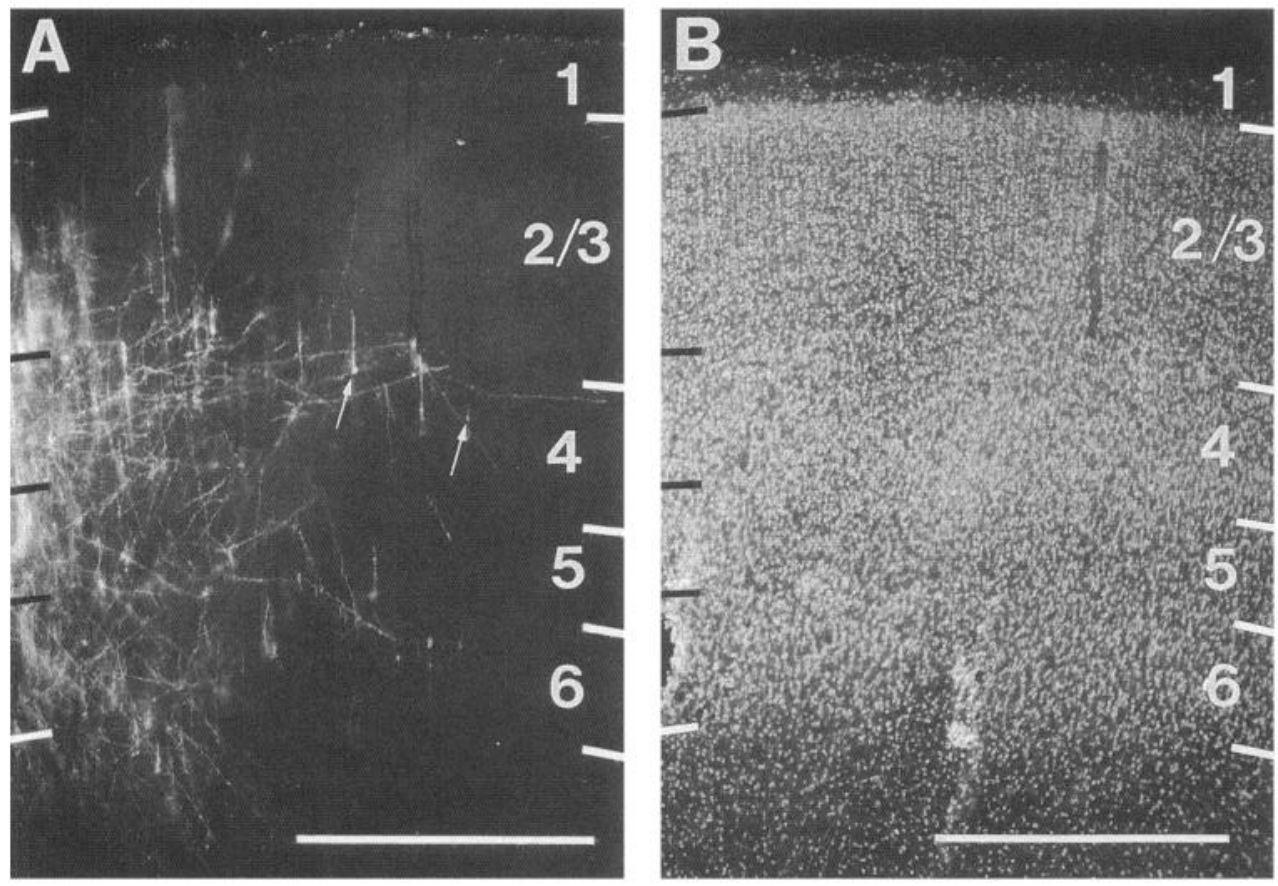

Figure 6. A, DiI injection into layers $2 / 3,4$, and 5 of primary visual cortex of 26-week-old human fetus. Margin of the injection site is at left border of photomicrograph. Short horizontal fibers travel along superficial border of layer 4 and along layer $5 / 6$ border. Labeled neurons at top of layer 4 (arrows) indicate that some horizontal fibers are local collaterals of cortical neurons and do not represent afferents from sources outside of V1. B, Fluorescence photomicrograph of bisbenzimide-stained section represented in $A$, showing emerging cortical layers. Scale bars, 0.5 $\mathrm{mm}$.

\section{Horizontal connections in 4-month-old infant}

The postnatal development of long-range projections within the superficial layers was surprisingly protracted. Seven weeks after birth, and even at 4 months of age (see Fig. 10A), the pattern of horizontal connections in every part of V1 was remarkably similar to that seen at around birth and essentially confined to layers $4 \mathrm{~B}, 5$, and 6 (Fig. $7 \mathrm{~A}$ ). This is astonishing considering that the $\mathrm{CO}$ pattern in superficial layers is present at birth and appears mature at 4 months postnatal. One day after birth, the $\mathrm{CO}$ staining was already nonuniform and showed an organized pattern of rows of $\mathrm{CO}$-rich blobs and $\mathrm{CO}$-poor interblobs (Fig. $8 B-D$ ). However, unlike in mature brains, the staining was weak, which made it difficult to measure the size of blobs accurately. Although the size range $(0.2-0.5 \mathrm{~mm})$ of blobs in newborns was broader than in 4 month olds, the center-to-center spacing $(0.6-$ $0.7 \mathrm{~mm}$ ) was similar, suggesting that the modular pattern does not obviously change after birth. At 4 months postnatal the $\mathrm{CO}$ staining pattern appeared mature and virtually identical to that of adults (Fig. 9; Horton and Hedley-Whyte, 1984; Burkhalter and Bernardo, 1989a). In V1, supragranular layers showed darkly stained blobs (diameter, $0.25-0.35 \mathrm{~mm}$; center-to-center spacing, $0.6-0.75 \mathrm{~mm}$ ) that were often connected through thin bridges with high enzymatic activity. In V2, CO staining revealed a regular pattern of dark (1-1.5 mm wide) and pale (2$2.5 \mathrm{~mm}$ wide) stripes in layer $2 / 3$ that ran perpendicular to the V1/V2 border. The staining within the stripes was nonuniform, indicating the presence of distinct subdivisions. Thus, even though the development of visual cortex had progressed to a stage where different functional compartments (DeYoe and Van Essen, 1988) could be distinguished anatomically, layer $2 / 3$ contained very few labeled fibers and tangentially spreading projections were confined to layers 4B, 5, and 6 (Fig. 10A). To ascertain that this result was real, we repeated the experiment $(n=10)$ by making much larger injections into layer $2 / 3$ (Fig. $10 \mathrm{C})$. In each case the outcome was the same, and we are con- fident that the labeling pattern is not due to the size and exact sublaminar location of the injection site.

\section{Horizontal connections in children aged 15 months to 5 years}

Although the laminar distribution of horizontal fibers remained unchanged during the first 4 months after birth, the fiber density in layers 4B, 5, and 6 increased dramatically (Figs. $7 A ; 10 A, C$; $11 A$ ). Similar to newborns, however, the fibers were uniformly distributed and the intralaminar termination pattern differed from the patchy pattern seen in layer 4B of a 5 year old (Fig. $11 C$ ). This suggests that patchy projections may form from initially more widespread projections that are subsequently pruned. However, the logical possibility exists that the uniform labeling at early ages is the result of injecting initially more closely spaced patches. The patchy layer $4 \mathrm{~B}$ projections shown in Figure $12 \mathrm{~A}$ indicated that this elimination was complete at 15 months of age. Because the elimination of inappropriate axon collaterals occurred after 4 months of age, it appears that the developmental signals that induce $\mathrm{CO}$ compartments in superficial layers are different from those that trigger the segregation of fibers into patchy projections within layer 4B.

Puzzled by the absence of local upper layer collaterals of layer $2 / 3$ cells at 4 months of age, a time when these cells have already developed long projections to layer 5 (Fig. 4), we wondered whether at this point other collateral projection systems of layer $2 / 3$ could be labeled by injections into superficial layers. For this purpose, we sought to label output and input fibers to and from V2. We therefore made DiI injections throughout the depth of V1 near the V1/V2 border. Figure 13 shows a case with large injections in layers $2 / 3$ and 4 and a smaller injection in lower layer 6 that included subcortical white matter. The result was unambiguous: a large number of labeled fibers passed through upper layers of V1 and entered V2, but very few horizontal fibers traveled in the opposite direction and penetrated deeper into the territory of V1. As expected, most fibers in the territory between the injection site and the V1/V2 border were un- 

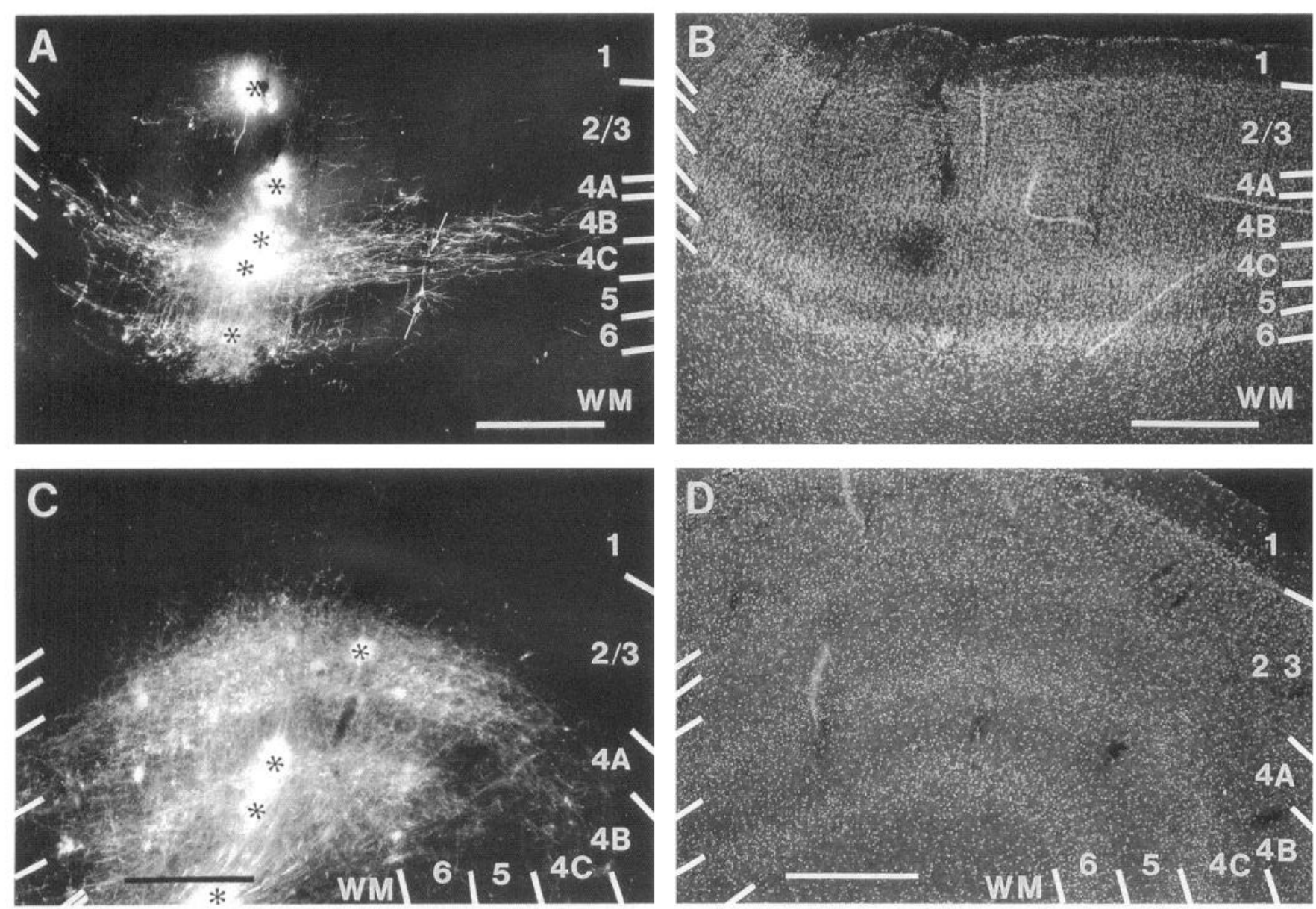

Figure 7. A, Five DiI injections (centers indicated with asterisks) distributed throughout the thickness of primary visual cortex in 37-week-old human fetus. Although all layers were injected (adjacent sections show that the injection reaches through the depth of layer $2 / 3$ ), the vast majority of horizontal fibers extend within layer $4 \mathrm{~B}$ and at the layer $5 / 6$ border. Layers superficial to layer 4B contain extremely few labeled fibers. Labeled cell bodies (arrows) indicate that at least some of the horizontal fibers represent local collaterals of cortical neurons. $B$, Section shown in $A$, counterstained with bisbenzimide. Notice sublamination within layer 4. $C$, DiI labeling in primary visual cortex of 1 -week-old neonate: multiple injections (asterisks) involving layers 4-6 and subcortical white matter $(W M)$. Unlike "clean" cortical injections $(A)$, white matter injections produce terminal labeling in layer $4 C$. $D$, Section shown in $C$, counterstained with bisbenzimide to reveal layers. Scale bars, $0.5 \mathrm{~mm}$.

branched. This abruptly changed in V2, where vertical collateral branches were abundant. Such branches were often found in projection targets, which suggests that we have labeled mainly fibers that go from V1 to V2. This result strongly indicates that extrinsic collaterals to V2 develop in advance of intrinsic collaterals within V1, and that it is unlikely that methodological problems account for the absence of horizontal projections within superficial layers of V1.

We are unable to tell exactly when upper layer long-range projections within V1 develop, because we have not had access to brains between the ages of 4 and 15 months. We do know, however, that these projections are present in a 15 month old. As in the 4-month-old case (Fig. 10), the injection that led to the labeling shown in Figure $12 A$ included all layers of the cortex. Unlike the pattern shown in Figure 10, $A$ and $C$, where labeling in upper layers was absent, Figure $12 A$ shows distinct projection clusters in layer $2 / 3,4 \mathrm{~B}$, and 5 . Although the projections within layer $2 / 3$ were clearly present, they were much sparser than in a 2 year old (Fig. 14A). This is interesting and supports the notion that at 15 months the projection is still immature.

By 2 years of age, for the first time, long-range projections within layer $2 / 3$ are robust and the density and patchiness of the projections resemble those seen in adults (Burkhalter and Bernardo, 1989a). Comparing the development of projections within layer $2 / 3$ and layer $4 \mathrm{~B}$, one can see similarities in that both projections were sparse initially (Figs. $7 A, 12$ ) and denser later in development (Figs. 10A,C;11A;14A). However, if one looks at patchiness, a striking difference becomes apparent: patches in layer 4B appear to develop from initially more widespread projections (Figs. $7 A ; 11 A, C ; 12 A$ ), whereas in layer $2 / 3$ patches were already present when the projections were still extremely weak (Fig. 12A). Thus, it appears that the patchy projections become increasingly refined by the elaboration of additional terminal branches (Fig. 14A).

At 5 years of age, the laminar pattern of long-ranging projections within V1 was similar to that at 2 years of age: clustered projections extended in layers $2 / 3,4 \mathrm{~B}, 5$, and 6 . Because the $\mathrm{CO}$ activity was well preserved in this case, we were able to test whether upper layer projections displayed the compartmental specificity known to exist in adults. For this purpose, attempts were made to target DiI injections into blobs or interblobs. The result of an interblob injection is shown in Figure 14, $B$ and $C$. (Notice that the spot labeled as the injection site is dark because of the purple color of DiI crystals and does not represent $\mathrm{CO}$ 

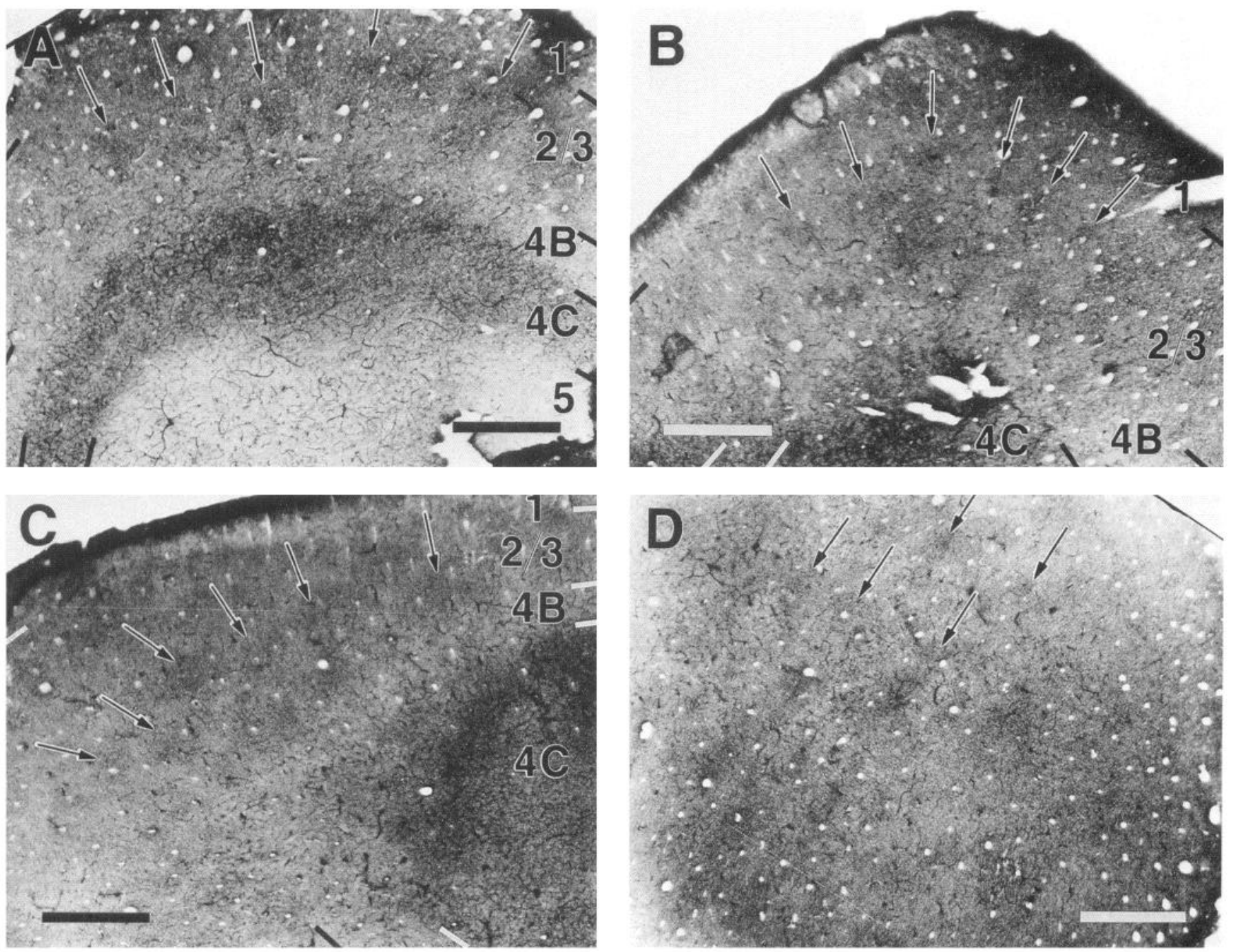

Figure 8. Distribution of $\mathrm{CO}$ activity in striate cortex of human neonate (1 d postnatal). A, Transverse section through $\mathrm{V} 1 \mathrm{showing}$ nonuniform staining in layer $2 / 3$ that resembles blobs (arrows). Dense staining is also seen in layer $4 \mathrm{C}$. There is no systematic difference in CO activity in superficial and deep parts of 4C. Although V1 contains a layer 4A, it does not express $\mathrm{CO}$ activity and can therefore not be distinguished from 4B. $B-D$, Horizontal section through $\mathrm{V} 1$ showing regular array of blobs (arrows). Scale bars, $1 \mathrm{~mm}$.

activity.) Although labeled fibers radiated from the injection site and arborized preferentially in nearby interblob regions, it is obvious that the segregation of inputs was incomplete since many fibers seemed to arborize at the boundaries between blobs and interblobs. Thus, it seems that this pattern reflects a developmental transition to the mature state where blobs are more exclusively connected to blobs and interblobs are linked to interblobs (Burkhalter and Bernardo, 1989a).

\section{Discussion}

Our work is the first description of development of local axonal connections within the visual cortex of humans. We have shown that local circuits within striate cortex are assembled in a sequence in which vertical connections between layers develop at the beginning of the third trimester of gestation, whereas long horizontal connections within layers do not emerge until shortly before birth and continue to develop throughout the first postnatal year and possibly beyond.

This pattern of cortical development is different from that deduced from a survey of the density of synaptic contacts in human visual cortex (Huttenlocher and de Courten, 1987). One of the important findings of this study was that the synaptic density in newborn human infants was extremely low. This gave rise to the idea that the intracortical circuitry is poorly developed at birth. Our findings indicate that this view is only partially correct and that the development of specific intracortical circuits (i.e., intracolumnar connections) is in fact remarkably advanced. In addition, we have shown that the development of intralaminar connections within superficial layers overlaps with the period during which synaptic density decreases (Huttenlocher and de Courten, 1987). Thus, our results indicate that the period of synapse elimination should not simply be regarded as a phase in development in which previously existing connections are lost. Rather, our evidence supports the interpretation that it is also a time that allows for the construction of new neuronal circuits. The important lesson from this is that it is necessary to determine the development of different subsets of projections to gain an understanding of the developmental status of the cortex. 
Figure 9. Reverse-contrast photomicrograph of horizontal section through flattened visual cortex of 4 month postnatal human stained for $\mathrm{CO}$ activity. V1 shows a mature pattern of blobs (light dots). V2 shows CO-rich stripes (arrows) that run perpendicular to the V1/V2 border. Staining within stripes is irregular, indicating compartmentalization of stripes. Scale bar, $5 \mathrm{~mm}$.

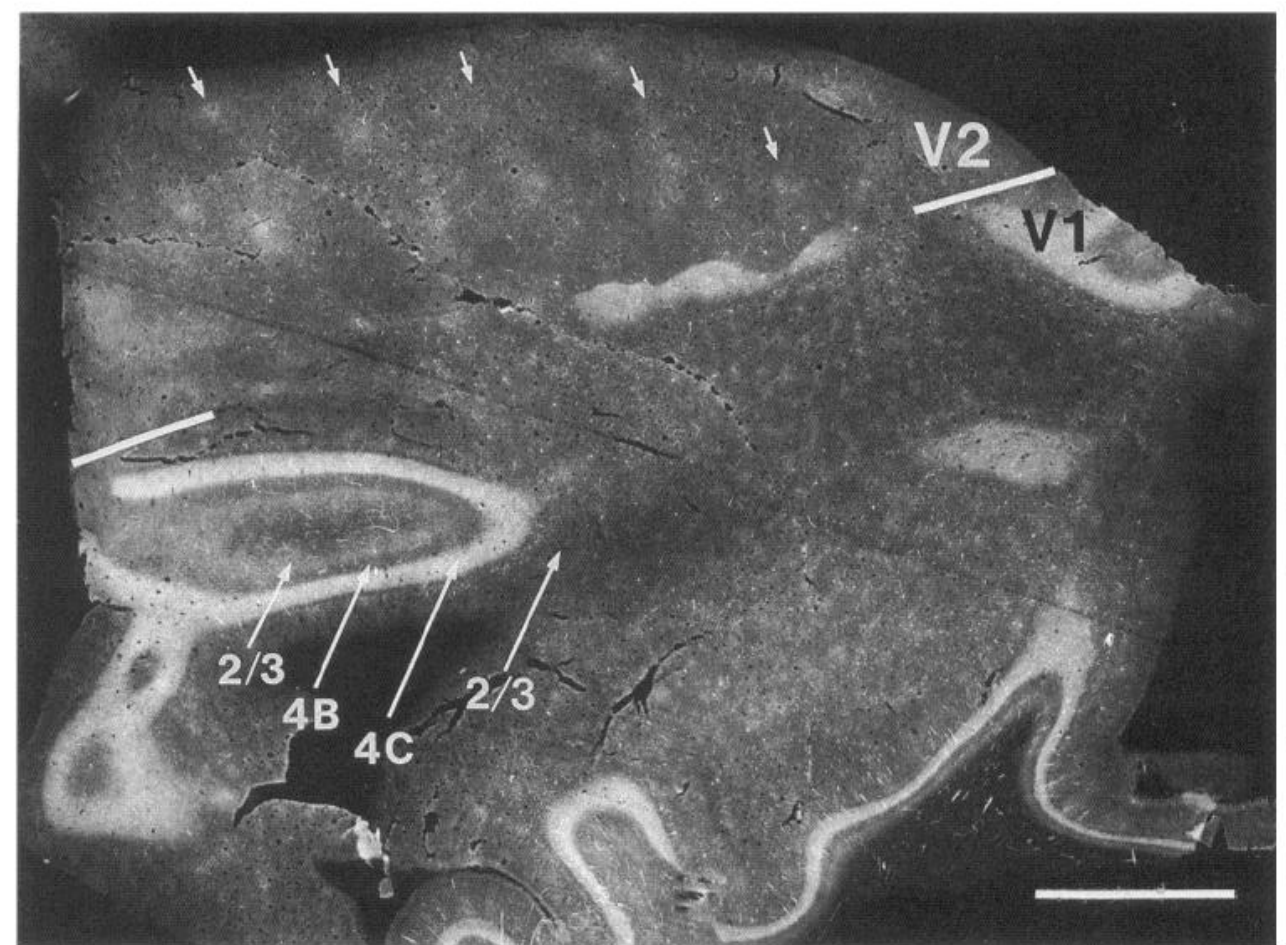

\section{Technical considerations}

Our work is the first effort aimed at determining local neuronal connections in developing human cortex. It is important here to explore several technical considerations upon which hinge the validity of our methods and results.

Working on the human brain imposes constraints that are experimentally more limiting than when working with experimental animals. Perhaps the least obvious of these is the availability of suitable material, which left us with significant gaps in the chronology of the development of intracortical connections.

An issue more pertinent for the interpretation of the results is whether the DiI labeling pattern was influenced by the postmortem interval before tissue fixation. It is well established that inappropriate fixation changes the integrity of cell membranes (Palay et al., 1962), which conceivably affects the intramembranous migration of DiI. Comparison of the DiI labeling patterns seen in immersion-fixed human striate cortex (Burkhalter and Bernardo, 1989a) with the labeling pattern produced by WGA-HRP observed in perfusion-fixed monkey visual cortex (Livingstone and Hubel, 1984a,b), however, indicates no apparent differences. Thus, it seems that axonal tracing with DiI provides an accurate picture of the organization of connections in the human brain.

Because DiI dissolves in cell membranes (Honig and Hume, 1986), it is likely that it is taken up by fibers of passage. This is a potential problem for identifying labeled fibers as local collaterals of cortical neurons and to discriminate these from extrinsic input fibers. The specific case we have to consider here is whether the labeled fibers in embryonic layer 4 (Figs. 6A, 7A) originate from layer 4 neurons, whether they could be recurrent axon collaterals of layer 6 pyramidal neurons (Lund and Boothe, 1975), or whether they represent geniculocortical afferents. The most direct way to answer the question would be to label the geniculocortical input with a second tracer and to look for overlap of labeling. We have not explored this possibility because of the length of the geniculocortical pathway and the prohibitively long transport time for the tracer. We are therefore forced to make an argument based on three sets of observations: (1) the presence of labeled neurons in layer 4B, (2) the laminar position of labeled fibers at the border between the granular layer and layer $2 / 3$, and (3) the presence of dense layer 4 labeling, only after white matter is included in the injection site (Fig. $7 C$ ). Each of these observations is consistent with the interpretation that the labeling in Figures $6 A$ and $7 A$ represents mainly intralaminar collateral projections of layer $4 \mathrm{~B}$ neurons.

Finally, a word to the sensitivity of the DiI tracing technique. How can we be sure that if we do not see labeled fibers in layer $2 / 3$ as late as 4 months after birth (Fig. 10), they are not there? To prove a negative result is a well-recognized problem. The important control here is that we were able to label fibers that link V1 and V2 in the very layer in which we failed to label local collaterals (Fig. 13). This rules out most technical explanations related to the duration of incubation, fixation, size, and location of injection site. Although the mean diameter of local collaterals is slightly smaller $(0.5-1 \mu \mathrm{m})$ than the caliber of interareal fibers $(0.75-1.5 \mu \mathrm{m})$, it seems unlikely that this could account for the difference. However, the logical possibility remains that for some unknown reasons immature local axon collaterals did not transport DiI. This seems unlikely because numerous examples indicate that unmyelinated or poorly myelinated axons, such as those in developing visual cortex, are labeled more readily than myelinated fibers (Honig and Hume, 1989). Nevertheless, it is important to interpret DiI tracing data with caution because similar transport times may yield different labeling patterns. For this reason, we have avoided conclusions based on the extent and density of projections. 

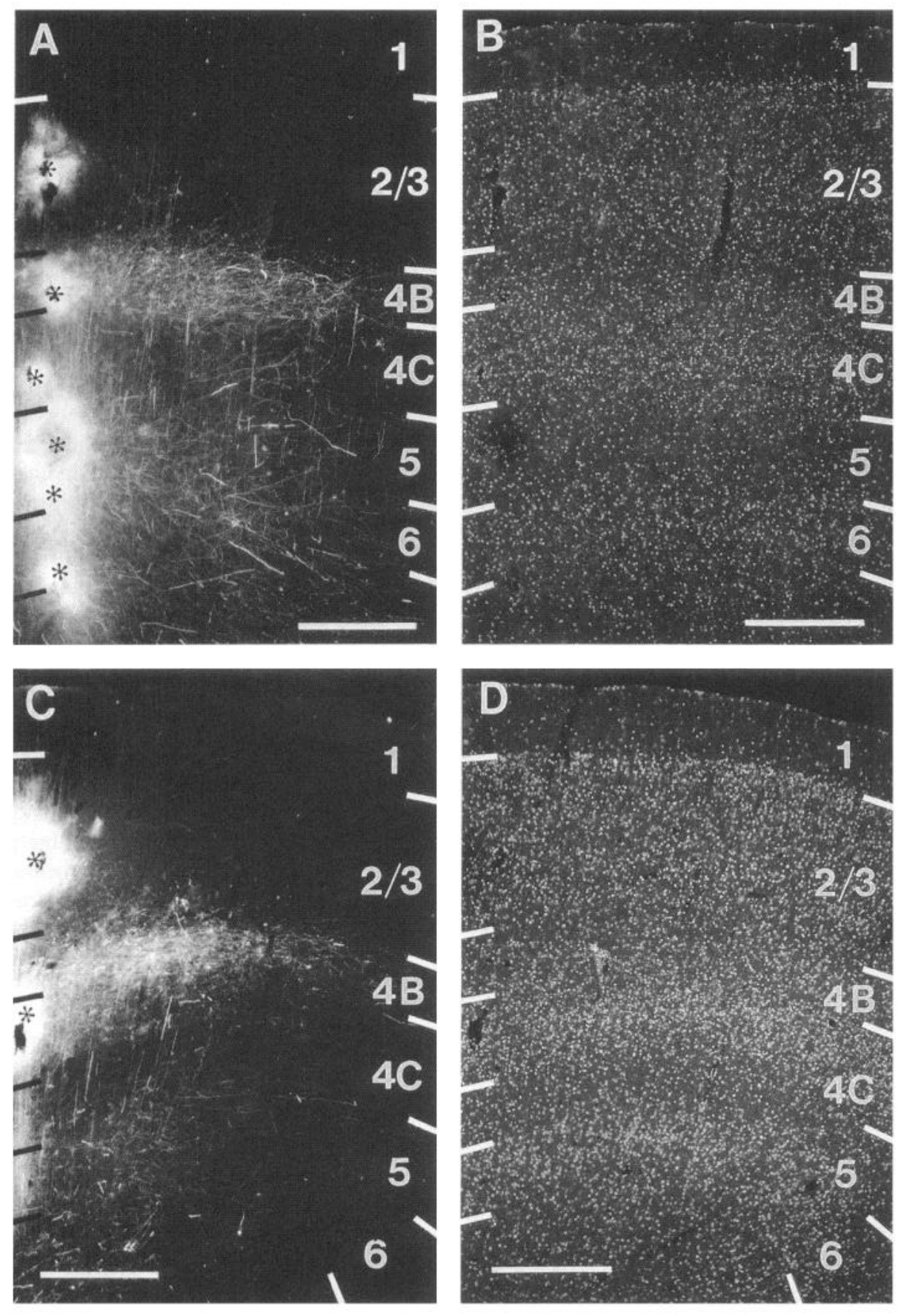

Figure 10. Postnatal development of horizontal connections in human primary visual cortex. $A$, Fluorescence photomicrograph of transverse section through V1 of 4 month postnatal human. Six DiI injections (asterisks mark centers) involving layers $2 / 3$ and $4 \mathrm{~B}-6$. Horizontal projections extend for more than $1.5 \mathrm{~mm}$ within layers $4 \mathrm{~B}, 5$, and 6. Within layer $4 C$, very few fibers travel horizontally and labeling is restricted to the immediate vicinity of the injection site. Within layer $2 / 3$, labeling is extremely sparse. The few fibers and cell bodies that are labeled are seen within $0.5 \mathrm{~mm}$ of the injection. $B$, Section shown in $A$, counterstained with bisbenzimide to reveal layers. Notice that the staining does not reveal layer 4A. $C$, Large Dil injections into layers $2 / 3$ and 4 of primary visual cortex of 4-month-old human. Although injection in layer $2 / 3$ is larger than in $A$, labeling in layer $2 / 3$ is extremely sparse and resembles that seen in $A$. $D$, Section shown in $C$, counterstained with bisbenzimide to reveal layers. Notice that staining does not reveal layer 4A. Scale bars, $0.5 \mathrm{~mm}$.

\section{Sequential development of vertical and horizontal connections: functional implications}

Our results provide evidence that at the time when neurons of the CP first develop local connections (26-29 weeks gestation) the $\mathrm{CP}$ is already innervated by afferents to striate cortex. Some of these afferents originate from subplate cells (Kostovic and Rakic, 1980), which we have always found directly below the injection site (Fig. 1D). This is consistent with laterally restricted projections to the $\mathrm{CP}$ and indicates that subplate cells in humans may resemble subplate cells in kitten visual cortex, which were found to project to middle and superficial layers of a column of cortex $\approx 400 \mu \mathrm{m}$ wide (Friauf et al., 1990). In addition to this input, we obtained evidence for afferents from the optic radi- ation (Fig. 3), which represent in all likelihood thalamocortical fibers. Kostovic and Rakic (1984), using AChE histochemistry, have postulated that these afferents originate from the pulvinar. However, recordings of visually evoked potentials in occipital cortex of a (25-week-old) preterm infant suggest that inputs also arise from the LGN (Purpura, 1975). The simultaneous presence of geniculocortical and subplate inputs is believed to be critical for the development of normal intracortical circuits (Friauf et al., 1990). In this view, it seems plausible that CP cells receive input from both small groups of spontaneously active LGN neurons and subplate cells (Gosh and Shatz, 1992) and that the interactions of these inputs may play a role in the columnar restriction of the interlaminar connections.

The most obvious difference in the local labeling pattern pro- 

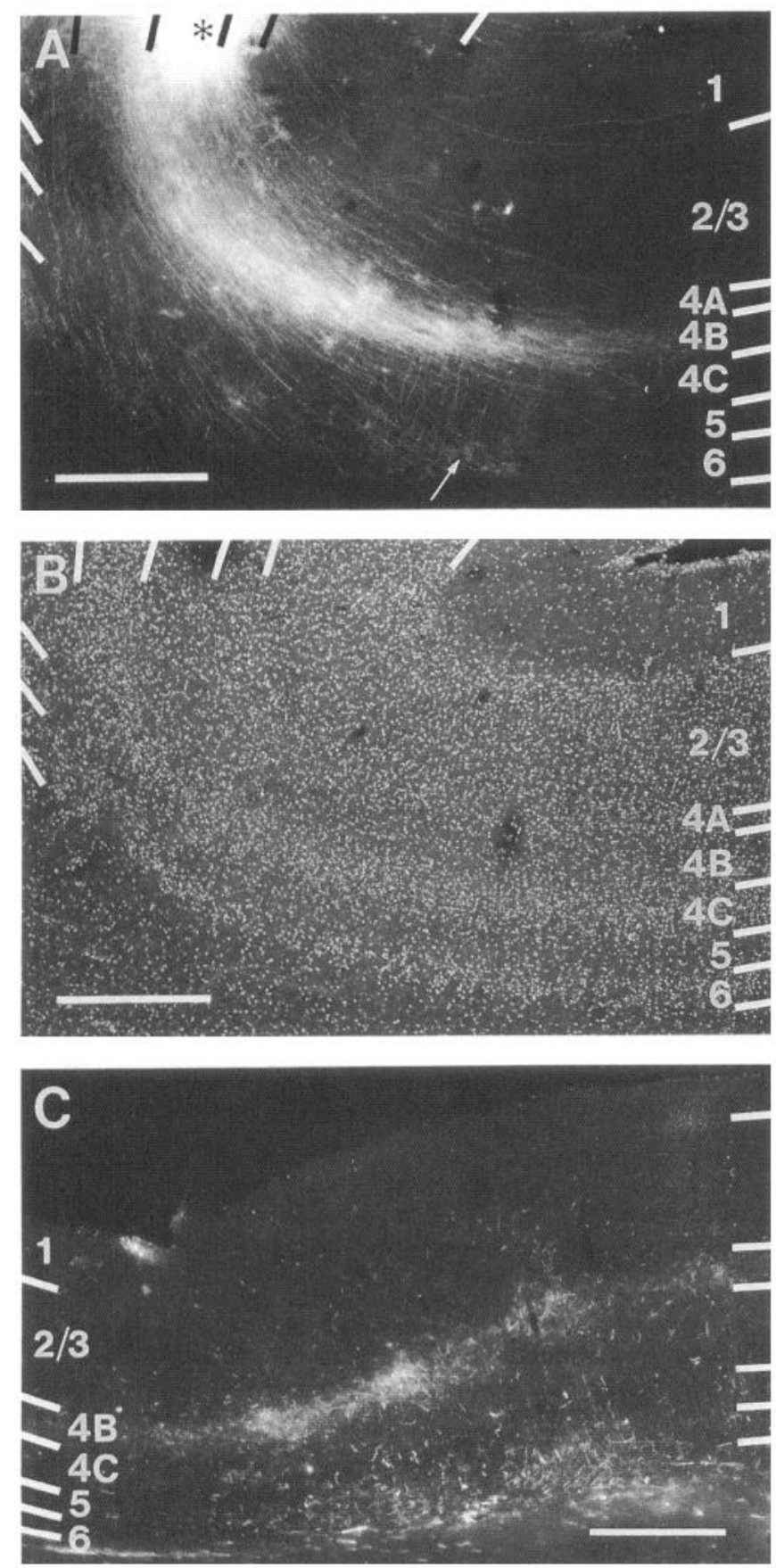

Figure 11. A, DiI injection (asterisk) into layer 4B of human primary visual cortex at 7 week postnatal. Most fibers are confined to layer $4 \mathrm{~B}$ and terminate in uniform fashion. Many fibers descend into subcortical white matter. Some fibers terminate in layer 6 (arrow). Projections to superficial layers ascend vertically, but laterally spreading fibers are extremely rare. $B$, Section shown in $A$, counterstained with bisbenzimide to reveal layers. $C$, Distribution of Dil-labeled axon arborizations in primary visual cortex after injection into layer $4 \mathrm{~B}$ of 5-year-old human. Layer $4 \mathrm{~B}$ contains clusters of terminal arborizations. Above layer 4B, labeling is extremely sparse. Below layer $4 \mathrm{~B}$, patches of axon arborizations are seen, although less dense in layer 6 . Scale bars, $0.5 \mathrm{~mm}$.

duced by upper layer injections in fetal and adult visual cortex is that fibers in layers $2 / 3$ and 5 of the adult brain extend far beyond the margins of the injection (Burkhalter and Bernardo, 1989a). In contrast, in the fetal brain extremely few collaterals extend laterally and the projection to layer 5 is in perfect vertical register with the injection site (Fig. 4). This indicates that connections that link similar points of the visuotopic map (Hubel and Wiesel, 1974) develop before lateral connections that link distant points of the topographic representation. Thus, it appears that connections within columns form before connections between columns. It is interesting that the establishment of intracolumnar connections in kitten visual cortex (Katz, 1991; Callaway and Katz, 1992) coincides with the time cells in all layers become visually responsive (Albus and Wolf, 1984). This indicates that the functional specification of columns through appropriate intracolumnar circuits precedes the linkage of functionally similar columns through horizontal connections (Livingstone and Hubel, 1984b; Burkhalter and Bernardo, 1989a; Gilbert and Wiesel, 1989). Since many of the basic response properties of cortical neurons are generated within columns of cortex $\approx 600 \mu \mathrm{m}$ wide, this could mean that the circuits for analyzing local features develop in advance of the circuits that are responsible for the integration of local features into a coherent image of the world.

Although based on the presence of terminal labeling in layer 5 this seems the most likely interpretation, we cannot rule out that part of the labeling is due to axon collaterals of layer 5 cells, rather than terminals of layer $2 / 3$ neurons. Such local collaterals may have accumulated DiI either through retrograde labeling of layer 5 neurons via projections to layer $2 / 3$ or through direct labeling via distal dendritic arbors. Unequivocal evidence against this scenario awaits reconstruction of the axonal projections of individual layer $2 / 3$ neurons. However, the absence of retrogradely labeled neurons in layers 4 and 6 , which in fetal monkey send axons to layer $3 \mathrm{~B}$ and whose dendrites do not rise above layer 4 (Lund et al., 1977), strongly suggests that the labeling pattern shown in Figure 4 is evidence that the reciprocal intracolumnar circuit between layers $2 / 3$ and 5 is mature at 29 weeks of gestation.

\section{Sequential development of $M$ - and P-horizontal circuits}

Association of layers $4 B$ and $2 / 3$ with $M$ - and $P$-processing stream. Studies in macaque monkey have shown that the main input to layer $4 \mathrm{~B}$ derives from the magnocellular LGN and is relayed through layer 4Ca (Hubel and Wiesel, 1972; Lund and Boothe, 1975). Within layer $4 \mathrm{~B}$ the input from a single point in space is distributed by an extensive network of lateral connections made by spiny pyramidal and stellate neurons (Rockland and Lund, 1983). It is likely that these intralaminar connections represent the horizontal fibers we have observed in layer $4 \mathrm{~B}$ of human striate cortex. Although this intralaminar network processes mainly signals from the M-pathway, layers $4 \mathrm{Ca}$ and $4 \mathrm{Cb}$ are interconnected through putative inhibitory interneurons (Lund, 1987), suggesting the possibility that layer 4B receives a mixture of $\mathrm{M}$ - and $\mathrm{P}$-inputs. In spite of this convergence, layer 4B shows a high incidence of directionally selective cells with high contrast and velocity sensitivities (Orban et al., 1986; Hawken et al., 1988), indicating a clear domination by inputs from the M-pathway.

In contrast to layer $4 \mathrm{~B}$, it is more ambiguous to relate the local projections within layer $2 / 3$ to a single processing stream. Recent evidence has shown that layer $2 / 3$ receives input from the M- and the P-pathway: parvocellular LGN input is conveyed through layers 4Cb and 4A (Lund and Boothe, 1975; Fitzpatrick et al., 1985), and M-input is relayed via layer 4Ca (Lachica et al., 1992) and layer 4B (Blasdel et al., 1985; Yoshioka and Lund, 1990). Although interblobs receive pure P-input and blobs are 


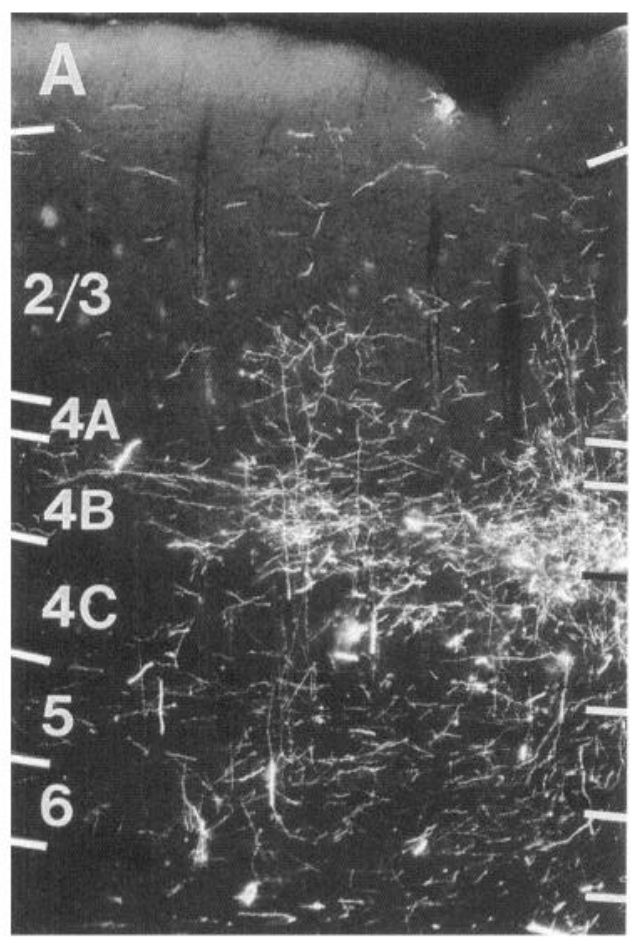

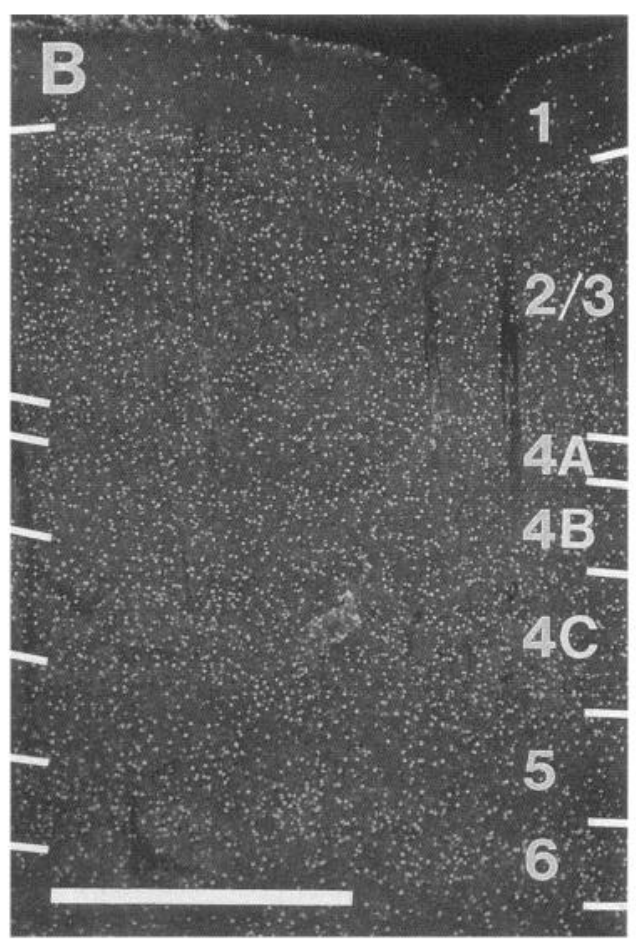

Figure 12. A, Fluorescence photomicrograph of DiI-labeled fibers in striate cortex of 15-month-old human. A radial row of DiI injections were made into layers $2 / 3-6$. Dense, clustered, horizontal projections are seen in layer $4 \mathrm{~B}$. Fibers and terminal arborizations are also seen in layers $2 / 3$ and 5 . Notice that although the projections in superficial layers are sparse, they are organized in distinct clusters. $B$, Section shown in $A$, counterstained with bisbenzimide to reveal layers. Scale bar, $0.5 \mathrm{~mm}$. supplied by M- and P-inputs (Lachica et al., 1992), because we have not stained every case for $\mathrm{CO}$ we are uncertain whether we have labeled connections between blobs or interblobs. However, for the purpose of this discussion it is important to stress that this shortcoming does not alter the interpretation that the M-dominated circuits within layer 4B develop in advance of the M- and P-related circuits in superficial layers (see below).

Different mechanisms for the formation of patchy projections within layers $4 B$ and $2 / 3$. Our results show that horizontal projections develop shortly before birth. Within layer 4B, collaterals proliferate rapidly during the first 2 postnatal months and soon blanket a large area with projections (Fig. 11 $\mathrm{A}$ ). These are subsequently remodeled into regular arrays of patches, presumably by a process of collateral elimination (Fig. 11C). Exactly when these patches are formed remains uncertain. All we know is that they appear after cortex has assumed the modular organization revealed by the blob pattern in striate cortex of newborns (Fig. 8 ), but it seems likely that the formation of patchy intracortical projections succeeds the segregation of geniculocortical afferents into ocular dominance columns, which is thought to be complete at 4-6 months postnatal (Hickey and Peduzzi, 1987). Similarly, there is uncertainty about the time of emergence of superficial layer projections. It is clear, however, that they develop after the projections within layer $4 \mathrm{~B}$. In addition, because layer $2 / 3$ projections appear to be patchy from the outset, it seems likely that they emerge after layer $4 \mathrm{~B}$ projections assume their patchy appearance.

We do not know for certain if the development of the circuitry within layer 4B (and layers 5 and 6) differs from that within layer $2 / 3$, nor do we understand why this may be so. However, it is interesting to note that the development of projections within layer $4 \mathrm{~B}$ resembles more closely that of geniculocortical afferents in layer $4 \mathrm{C}$ than that of intracortical projections. Intracortical projections typically develop from widely spread groups of neurons, but their terminations emerge with a fair amount of topographic precision (Innocenti, 1981; Price and Zumbroich, 1989; Callaway and Katz, 1990; Fish et al., 1991). By contrast, in layer $4 \mathrm{C}$ overlapping inputs from the two eyes are gradually segregated over a period that in monkeys extends from late gestation to the second postnatal month (Rakic, 1977b; LeVay et al., 1980). This formation of ocular dominance columns is correlated with the acquisition of stereopsis (LeVay et al., 1978; Timney, 1981). Thus, it is possible that the formation of patchy projections within layer $4 \mathrm{~B}$ may be synchronous with the emergence of disparity-selective mechanisms that are essential for stereoscopic vision. These disparity-selective binocular interactions may be important for the maturation of direction-selective mechanisms in layer 4B. Specifically, it is possible that they contribute to the loss of the initial bias to nasally directed motion, recorded in striate cortex (Hamer et al., 1990) and observed in humans with arrested binocular development (Tychsen and Lisberger, 1986). As a matter of fact, Tychsen (1992a) has argued that the acquisition of symmetrical motion processing is dependent upon the development of normal connections within layer $4 \mathrm{~B}$. In contrast, connections within layer $2 / 3$ develop long after ocular dominance columns have formed and binocular connections have been established. Layer $2 / 3$ neurons may therefore need to receive correlated binocular inputs from topographically corresponding points before they can develop horizontal collaterals. Indeed, recent findings in the cat have shown that normal binocular experience is important for the development of topographically precise connections within upper layers of cat striate cortex (Löwel and Singer, 1992). Preliminary results in naturally strabismic monkey suggest that similar mechanisms may play a role in establishing appropriate connections for binocular vision within primate primary visual cortex (Tychsen and Burkhalter, 1992).

Functional implications. The finding that horizontal intralaminar connections within layer 4B develop before similar connections emerge in layer $2 / 3$ suggests that intracortical circuits 


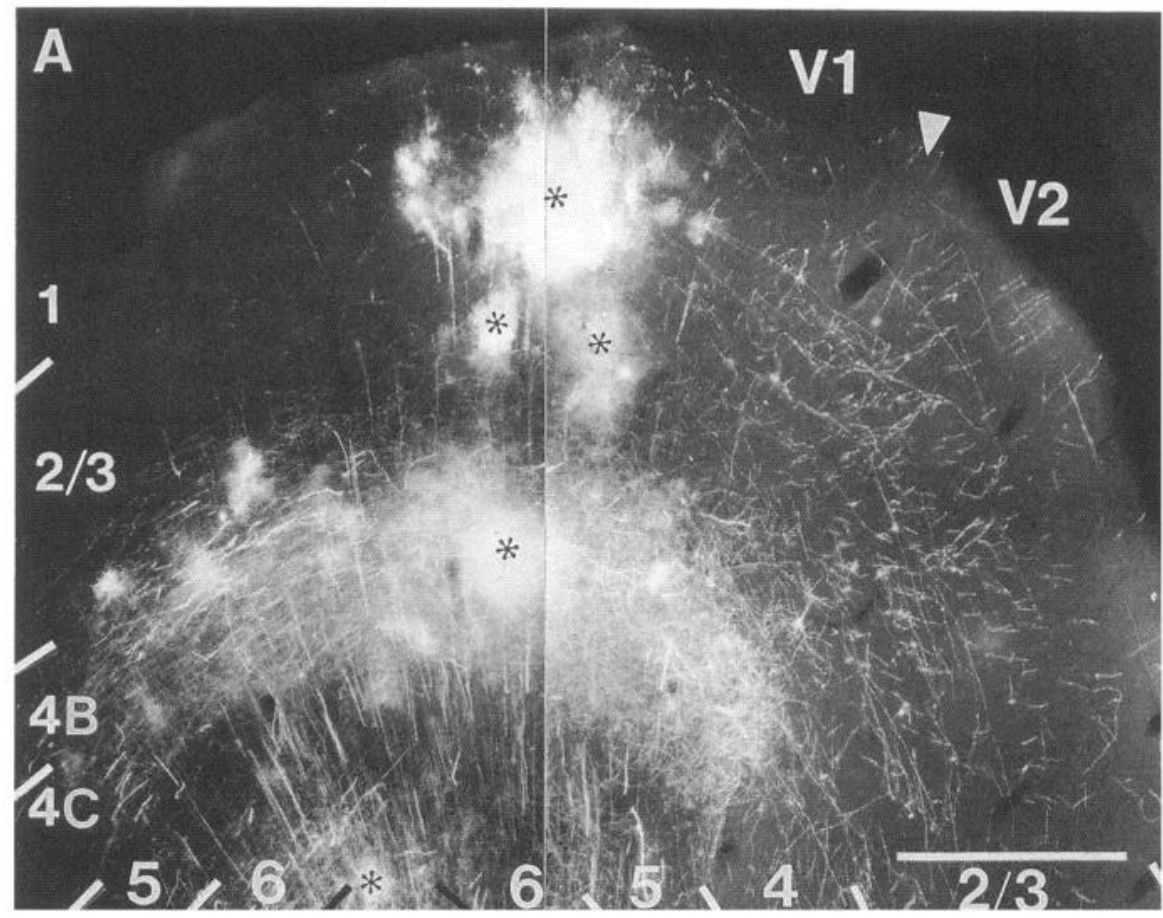

Figure 13. A, Montage of photomicrographs showing DiI injections into primary visual cortex of 4-month-old human. Injections (asterisks) are located near the V1/V2 border (arrowhead). Within V1, fiber labeling is dense in layers $4 \mathrm{~B}$ and 6 . Labeling in layer $2 / 3$ is asymmetrical: extremely few fibers are seen within V1 on the left of the injection site, whereas numerous fibers are seen on the right, many of which cross the V1/V2 border and penetrate deep into V2. Within V2 fibers give off vertical collaterals, indicating terminal projections. $B$, Montage shown in $A$, counterstained with bisbenzimide to reveal layers and areal boundaries. V1/ $\mathrm{V} 2$ border is indicated by broken line. Scale bars, $0.5 \mathrm{~mm}$.

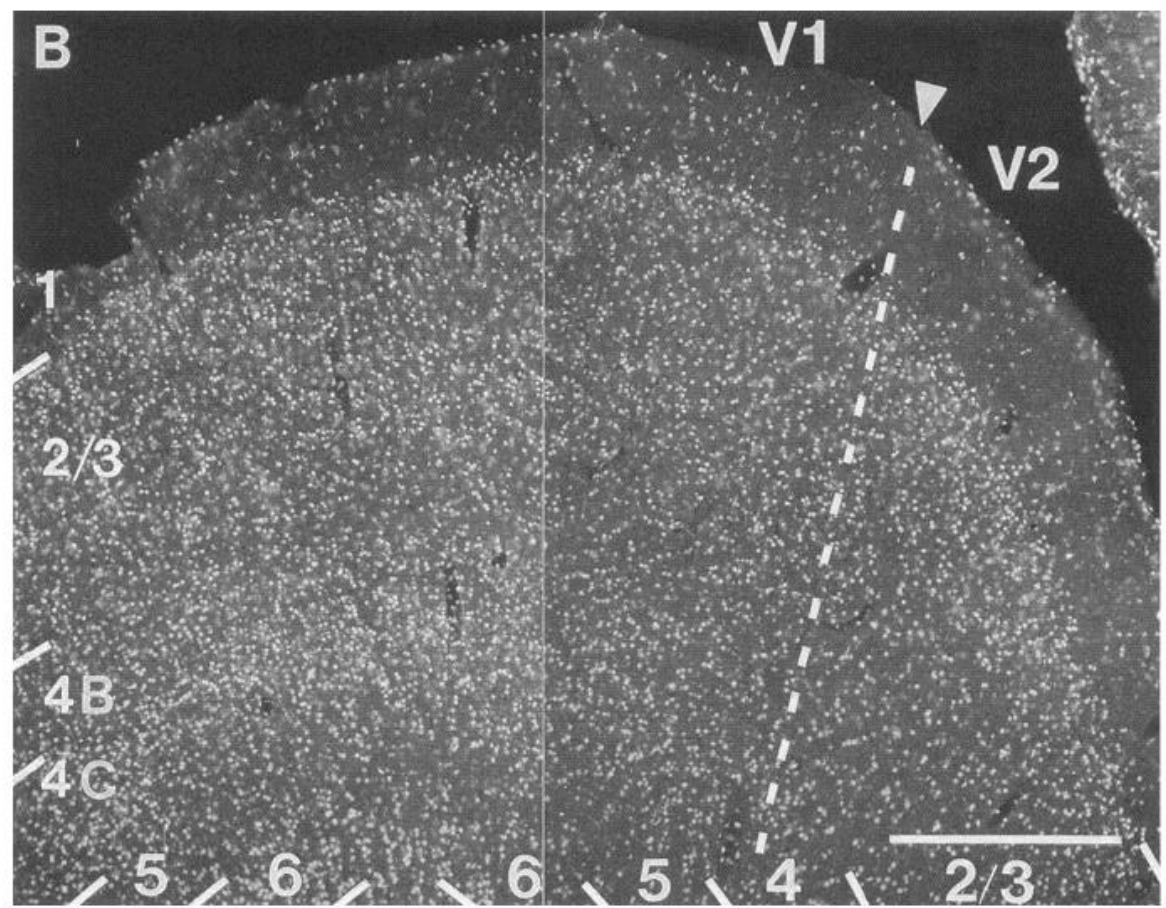

related to the M-pathway mature before circuits associated with the P-pathway. To the extent that the M-pathway contributes to motion processing (Schiller et al., 1990; Merigan et al., 1991b) and the P-pathway (Schiller et al., 1990; Merigan et al., 1991a) contributes to form and color vision, this scheme agrees with the general notion that object recognition in infants is more dependent on motion information than on static information (Kellman and Spelke, 1983; Kellman, 1984; Dannemiller and Freedland, 1989) and emerges before precise form and color vision (for review see Tychsen, 1992b).

Support for an early development of the M-pathway derives from birth dating of LGN neurons in monkey, which shows that M-layers are generated before P-layers (Rakic, 1977a). In addition, Garey and Saini (1981) have shown that in monkey, M-neurons assume the mature morphology in advance of P-neurons. Surprisingly, despite the developmental lead of M-neurons, geniculocortical fibers arrive simultaneously in layers $4 \mathrm{Ca}$ and $4 \mathrm{Cb}$ of monkey striate cortex (Rakic, 1977b). Whether this indicates that synapses in $4 \mathrm{Ca}$ and $4 \mathrm{Cb}$ become functional at the same time is not known, although the synchronous development of geniculocortical M- and P-axons in Galago (Florence and Casagrande, 1990) suggest that they may do so. What is known, however, is that the synaptic density in layer $4 \mathrm{~B}$ is maximal at 4 months of age, which is 4 months earlier than 

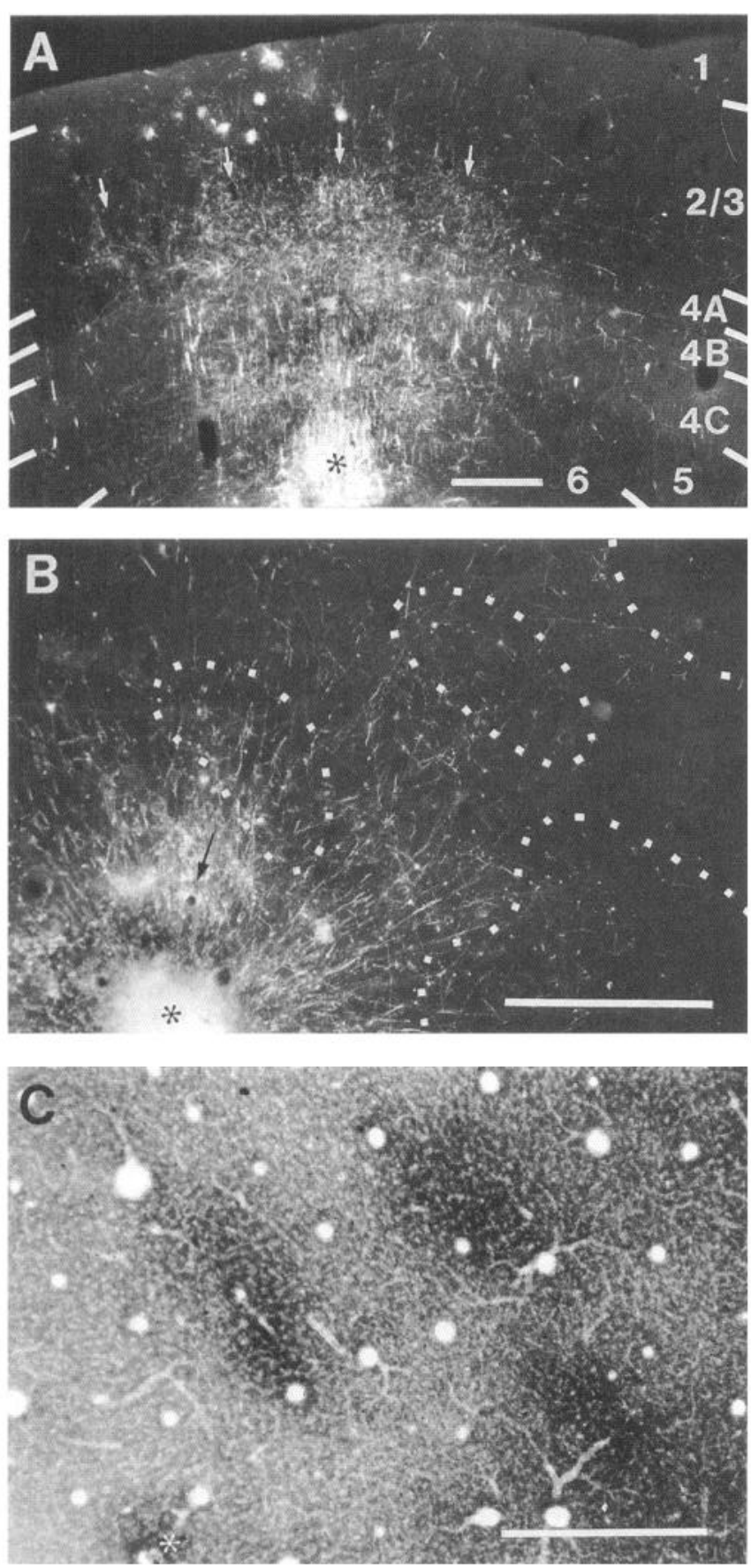

Figure 14. A, DiI-labeled projections within primary visual cortex after injection through depth of gray matter in 2-year-old human. Coronal section taken near the injection site (lowermost extension marked with asterisk) shows long-ranging axonal projections within layers $2 / 3,4 \mathrm{~B}$, 5 , and 6 . Terminal arborizations are distributed in nonuniform fashion and appear clustered (arrows). B, Horizontal section through primary visual cortex of 5-year-old human: DiI injection into interblob (asterisk). Local projections are widespread and tend to arborize in interblob regions. Most prominent interblob projection site is marked by arrow. Blobs are outlined by white dots. $C$, $\mathrm{CO}$ staining pattern in section adjacent to that shown in $B$ (compare blood vessels). Injection site (asterisk) is dark because of purple color of DiI crystals and does not represent increased $\mathrm{CO}$ activity. Notice that fibers preferentially arborize within interblob regions. Scale bars, $0.5 \mathrm{~mm}$. layers $2 / 3,4 \mathrm{C}$, and 5 reach the same state (Huttenlocher and de Courten, 1987). Interestingly, the laminar sequence in which layers become myelinated follows a similar pattern (Conel, 19391967). These results strongly suggest that functional circuits within layer 4B mature before those in other layers. Furthermore, Flechsig's (1904) finding that area 12, the putative human homologue of area MT (Clarke and Miklossy, 1990; Corbetta et al., 1991) and likely projection target of layer 4B (Maunsell and Van Essen, 1983), becomes myelinated in advance of other extrastriate visual areas suggests that the precocious developmental schedule of layer $4 \mathrm{~B}$ may extend throughout the entire M-pathway.

It is interesting to ask whether this sequential maturation of intracortical circuits is consistent with the development of visual perception in infants. A large number of behavioral and electrophysiological studies strongly indicate that this is the case. One of the most compelling findings for the sequential development of M- and P-related mechanisms derives from visual evoked potential studies of the development of contrast sensitivity. They show that adult contrast sensitivity is reached at 9 weeks of age and that the increase in acuity between 2 and 8 months of age is determined purely by an improvement in spatial resolution (Norcia and Tyler, 1985; Norcia et al., 1990). Directional selectivity develops shortly after contrast sensitivity has reached maturity (Wattham-Bell, 1991). Since directionally selective mechanisms originate in the cortex (Hubel and Wiesel, 1968), this suggests that the ability to discriminate the direction of local motion at 8 weeks postnatal (Wattham-Bell, 1992) is correlated with the emergence of circuits within layer 4B (Figs. $7 A, 11 A, C)$.

The P-channel mediates information that is necessary for the perception of color, texture, shape, pattern, and stereopsis (DeYoe and Van Essen, 1988; Schiller et al., 1990). All of these functions are encoded by neurons in the cortex that acquire their selective receptive field properties through specific intracortical connections. Among these are horizontal connections within layer $2 / 3$ that form distinct networks between color-selective blobs and between orientation-selective interblobs (Livingstone and $\mathrm{Hu}$ bel, 1984b; Burkhalter and Bernardo, 1989a). These connections form after 4 months postnatal and may assume maturity at 15 months of age. Thus, outgrowth of horizontal collaterals from upper layer cells of the color and form channel are delayed until at least 4 months of age, when orderly maps of blobs and interblobs have fully matured (Fig. 9; Horton and Hedley-White, 1984). At this time, infants have good color (Brown, 1990) and stereoscopic vision (Birch et al., 1982) and are able to discriminate orientations (Braddick et al., 1986; Atkinson et al., 1989). Interestingly, the ability to perform figure-ground discriminations, a task that requires the comparison of orientation-selective responses in distant points of the visual field, matures over an extended period and does not reach adult levels until after 1 year of age (Atkinson and Braddick, 1992; Sireteanu and Rieth, 1992). Since it appears that texture segregation may be processed preferentially in primary visual cortex (Lamme et al., 1992), it is possible that the neural basis for this may lie in the late formation of horizontal connections within superficial layers that we have described in this report.

\section{References}

Albus K, Wolf W (1984) Early post-natal development of neuronal function in the kitten's striate cortex: a laminar analysis. J Physiol (Lond) 384:153-185. 
Atkinson J (1984) Human visual development over the first 6 months of life. A review and a hypothesis. Hum Neurobiol 3:61-74.

Atkinson J, Braddick O (1992) Visual segmentation of oriented textures by infants. Behav Brain Res 49:123-131.

Atkinson J, Hood B, Wattham-Bell J, Anker S, Tricklebank J (1989) Development of orientation discrimination in infancy. Perception 17: 587-595.

Birch EE, Gwiazda J, Held R (1982) Stereoacuity development for crossed and uncrossed disparity in human infants. Vision Res 22: 507-513.

Blasdel GG, Lund JS (1983) Termination of afferent axons in macaque striate cortex. J Neurosci 3:1389-1413.

Blasdel GG, Lund JS, Fitzpatrick D (1985) Intrinsic connections of macaque striate cortex: axonal projections of cells outside lamina $4 \mathrm{C}$. J Neurosci 5:3350-3369.

Bolz J, Gilbert CD (1986) Generation of end-inhibition in the visual cortex via interlaminar connections. Nature 320:362-365.

Boothe RG, Dobson V, Teller DY (1985) Postnatal development of vision in human and nonhuman primates. Annu Rev Neurosci 8:495545.

Braak H (1984) Architectonics as seen by lipofuscin stains. In: Cerebral cortex, Vol 1 (Peters A, Jones EG, eds), pp 59-104. New York: Plenum.

Braddick OJ, Wattham-Bell J, Atkinson J (1986) Orientation specific cortical responses develop early in infancy. Nature 320:617-619.

Brown AM (1990) Development of visual sensitivity to light and color vision in human infants: a critical review. Vision Res 30:1159-1188.

Burkhalter A, Bernardo K L (1989a) Organization of corticocortical connections in human visual cortex. Proc Natl Acad Sci USA 86: $1071-1075$.

Burkhalter A, Bernardo KL (1989b) Development of local connections in human visual cortex. Soc Neurosci Abstr 15:2.

Burkhalter A, Bernardo KL, Charles V (1990) Postnatal development of intracortical connections in human visual cortex. Soc Neurosci Abstr 16:1129.

Callaway EM, Katz LC (1990) Emergence and refinement of clustered horizontal connections in cat striate cortex. J Neurosci 10:1134-1153.

Callaway EM, Katz LC (1992) Development of axonal arbors of layer 4 spiny neurons in cat striate cortex. J Neurosci 12:570-582.

Chapman B, Zahs KR, Stryker MP (1991) Relation of cortical cell orientation selectivity to alignment of receptive fields of the geniculocortical afferents that arborize within a single orientation column in ferret visual cortex. J Neurosci 11:1347-1358.

Chatel M (1976) Developpement de l'isocortex du cerveau humain pendant les periodes embryonnaires et foetales jusqu'a la $24 \mathrm{eme}$ semaine de gestation. J Hirnforsch 17:189-212.

Clarke S, Miklossy J (1990) Occipital cortex in man: organization of callosal connections, related myelo- and cytoarchitecture, and putative boundaries of functional visual arcas. J Comp Neurol 298:188214.

Conel JL (1939-1967) The postnatal development of the human cerebral cortex, Vols I-VII. Cambridge: Harvard UP.

Corbetta M, Miezin FM, Dobmeyer S, Shulman GL, Petersen SE (1991) Selective and divided attention during visual discriminations of shape, color and speed: functional anatomy by positron emission tomography. J Neurosci 11:2383-2402.

Dannemiller JL, Freedland RL (1989) The detection of slow stimulus movement in 2-5 month-olds. J Exp Child Psychol 47:337-355.

DeYoe EA, Van Essen DC (1988) Concurrent processing streams in monkey visual cortex. Trends Neurosci 11:219-226.

Fish SE, Rhoades RW, Bennett-Clarke LA, Figley B, Mooney RD (1991) Organization, development and enucleation-induced alterations in the visual callosal projection of the hamster: single axon tracing with Phaseolus vulgaris leucoagglutinin and Di-I. Eur J Neurosci 3:12551270.

Fitzpatrick D, Lund JS, Blasdel GG (1985) Intrinsic connections of macaque striate cortex: afferent and efferent connections of lamina 4C. J Neurosci 5:3329-3349.

Flechsig P (1904) Einige Bemerkungen über die Untersuchungsmethoden der Grosshirnrinde insbesondere des Menschen. Ber Verh k sächs Ges Wiss Leipz Math Phys Klasse 56:50-104, 177-248.

Florence SL, Casagrande VA (1990) Development of geniculocortical axon arbors in a primate. Vis Neurosci 5:291-309.

Friauf E, McConnell SK, Shatz CJ (1990) Functional synaptic circuits in the subplate during fetal and early postnatal development of cat visual cortex. J Neurosci 10:2601-2613.
Garey LJ, Saini KD (1981) Golgi studies of the normal development of neurons in the lateral geniculate nucleus of the monkey. Exp Brain Res 44:117-128.

Gilbert CD (1983) Microcircuitry of the visual cortex. Annu Rev Neurosci 6:217-247.

Gilbert CD, Wiesel TN (1983) Clustered intrinsic connections in cat visual cortcx. J Ncurosci 3:1116-1133.

Gilbert CD, Wiesel TN (1989) Columnar specificity of intrinsic horizontal connections in cat visual cortex. J Neurosci 9:2432-2442.

Godement P, Vanselow J, Thanos S, Bonhoeffer F (1987) A study in developing systems with a new method of staining neurones and their processes in fixed tissue. Development 101:697-713.

Gosh A, Shatz CJ (1992) Involvement of subplate neurons in the formation of ocular dominance columns. Science 255:1441-1443.

Grieve KL, Sillito AM (1991) A re-appraisal of the role of layer VI of the visual cortex in the generation of cortical end inhibition. Exp Brain Res 87:521-529.

Hamer RD, Norcia AM, Orel-Bixler D, Hoyt CS (1990) Cortical responses to nasal and temporal motion are asymmetric in early but not late-onset strabismus. Invest Ophthalmol Vis Sci [Suppl] 31:289.

Hawken MJ, Parker AJ, Lund JS (1988) Laminar organization and contrast sensitivity of direction-selective cells in the striate cortex of the old world monkey. J Neurosci 8:3541-3548.

Hickey TL, Peduzzi JD (1987) Structure and development of the visual system. In: Handbook of infant perception (Salapatek P, Cohen L, eds), pp 1-42. New York: Academic.

Honig MG, Hume RI (1986) Fluorescent carbocyanine dyes allow living neurons of identified origin to be studied in long-term cultures. J Cell Biol 103:171-187.

Honig MG, Hume RI (1989) DiI and DiO: versatile fluorescent dyes for neuronal labelling and pathway tracing. Trends Neurosci 12:333341.

Horton JC, Hedley-Whyte TE (1984) Mapping of cytochrome oxidase patches and ocular dominance columns in human visual cortex. Philos Trans R Soc Lond [Biol] 304:255-272.

Hubel DH, Wiesel TN (1968) Receptive fields and functional architecture of monkey striate cortex. J Physiol (Lond) 195:215-243.

Hubel DH, Wiesel TN (1972) Laminar and columnar distribution of geniculo-cortical fibers in the macaque monkey. J Comp Neurol 146: $421-450$.

Hubel DH, Wiesel TN (1974) Uniformity of monkey striate cortex: a parallel relationship between field size, scatter and magnification factor. J Comp Neurol 158:295-306.

Hubel DH, Wiesel TN (1977) Functional architecture of macaque visual cortex. Proc R Acad Sci Lond [Biol] 198:1-59.

Huttenlocher PR, de Courten C (1987) The development of synapses in striate cortex of man. Hum Neurobiol 61:1-9.

Innocenti GM (1981) Growth and reshaping of axons in the establishment of visual connections. Science 212:824-827.

Katz LC (1991) Specificity in the development of vertical connections in cat striate cortex. Eur J Neurosci 3:1-9.

Katz LC, Callaway EM (1992) Development of local circuits in mammalian visual cortex. Annu Rev Neurosci 15:31-56.

Kellman PJ (1984) Perception of three-dimensional from by human infants. Percept Psychophys 36:353-358.

Kellman PJ, Spelke ES (1983) Perception of partly occluded objects in infancy. Cogn Psychol 15:483-524.

Kostovic I, Rakic P (1980) Cytology and time of origin of interstitial neurons in the white matter in infant and adult human and monkey tclencephalon. J Neurocytol 9:210-242.

Kostovic I, Rakic P (1984) Development of prestriate visual projections in the monkey and human fetal cerebrum revealed by transient cholinesterase staining. J Neurosci 4:25-42.

Lachica EA, Beck PD, Casagrande VA (1992) Parallel pathways in macaque monkey striate cortex: anatomically defined columns in layer III. Proc Natl Acad Sci USA 89:3566-3570.

Lamme VAF, Van Dijk BW, Sperkreijse H (1992) Texture segregation is processed by primary visual cortex in man and monkey. Evidence from VEP experiments. Vision Res 32:797-807.

LeVay S, Hubel DH, Wiesel TN (1980) The development of ocular dominance columns in normal and visually deprived monkeys. $\mathrm{J}$ Comp Neurol 191:1-51.

LeVay S, Stryker MP, Shatz CJ (1978) Ocular dominance columns and their development in layer IV of the cat's visual cortex: a quantitative study. J Comp Neurol 179:223-244. 
Livingstone MS, Hubel DH (1984a) Anatomy and physiology of a color system in the primate visual cortex. J Neurosci 4:309-356.

Livingstone MS, Hubel DH (1984b) Specificity of intrinsic connections in primate primary visual cortex. J Neurosci 4:2830-2835.

Löwel S, Singer W (1992) Selection of intrinsic horizontal connections in the visual cortex by correlated activity. Science 255:209-212.

Lund JS (1987) Local circuit neurons of macaque monkey striate cortex: I. Neurons of laminae 4C and 5A. J Comp Neurol 257:6092.

Lund JS, Boothe RG (1975) Interlaminar connections and pyramidal neuron organization in the visual cortex, area 17, of the macaque monkey. J Comp Neurol 159:305-334.

Lund JS, Boothe RG, Lund RD (1977) Development of neurons in he visual cortex (area 17) of the monkey (Macaca nemestrina): a Golgi study from fetal day 127 to postnatal maturity. J Comp Neurol 176: 149-188.

Marin-Padilla M, Marin-Padilla MT (1982) Origin, prenatal development and structural organization of layer $I$ of the human cerebral (motor) cortex. Anat Embryol (Berl) 164:161-206.

Maunsell JHR, Van Essen DC (1983) The connections of the middle temporal visual area (MT) and their relationship to a cortical hierarchy in the macaque monkey. J Neurosci 3:2563-2586.

McConnell SK, Gosh A, Shatz CJ (1989) Subplate neurons pioneer the first axon pathway from the cerebral cortex. Science 245:978982.

Merigan WH, Katz LM, Maunsell JHR (1991a) The effects of parvocellular lateral geniculate lesions on the acuity and contrast sensitivity of macaque monkey. J Neurosci 11:994-1001.

Merigan WH, Byrne CE, Maunsell JHR (1991b) Does primate motion perception depend on the magnocellular pathway? J Neurosci 11: 3422-3429.

Molliver ME, Kostovic I, Van Der Loos H (1973) The development of synapses in cerebral cortex in the human fetus. Brain Res 50:403407.

Morrone MC, Burr DC (1986) Evidence for the existence and development of visual inhibition in humans. Nature 321:235-237.

Nealey TA, Maunsell JHR (1991) Magnocellular contributions to the superficial layers of macaque striate cortex. Invest Ophthalmol Vis Sci [Suppl] 32:1117.

Norcia AM, Tyler CW (1985) Spatial frequency sweep VEP: visual acuity during the first year of life. Vision Res 25:1399-1408.

Norcia AM, Tyler CW, Hamer RD (1990) Development of contrast sensitivity in the human infant. Vision Res 30:1475-1486.

Olavarria J, Van Sluyters RC (1985) Unfolding and flattening the cortex of gyrencephalic brains. J Neurosci Methods 15:191-202.

Orban GA, Kennedy H, Bullicr J (1986) Velocity sensitivity of neurons in areas V1 and V2 of the monkey: influence of eccentricity. J Neurophysiol 56:462-480.

Palay SL, McGee-Russell SM, Gordon S, Grillo MA (1962) Fixation of neural tissues for electron microscopy by perfusion with solutions of osmium tetroxide. J Cell Biol 12:385-410.

Price DJ, Zumbroich TJ (1989) Postnatal development of corticocortical efferents from area 17 in the cat's visual cortex. J Neurosci 9:600-613.

Purpura DP (1975) Morphogenesis of visual cortex in the preterm infant. In: Growth and development of the brain (Brazier MAB, ed), pp 33-49. New York: Raven.
Rakic P (1972) Mode of cell migration to the superficial layers of fetal monkey neocortex. J Comp Neurol 145:61-84.

Rakic P (1977a) Genesis of the dorsal lateral geniculate nucleus in the rhesus monkey: site and time of origin, kinetics of proliferation, routcs of migration and pattern of distribution of neurons. J Comp Neurol 176:23-52.

Rakic P (1977b) Prenatal development of the visual system in the rhesus monkey. Phil Trans R Soc Lond [Biol] 278:254-260.

Rakic P (1978) Neuronal migration and contact guidance in the primate telencephalon. Postgrad Med J [Suppl] 54:25-37.

Rockland KS, Lund JS (1983) Intrinsic laminar lattice connections in primate visual cortex. J Comp Neurol 216:303-318.

Schiller PH, Logothetis NK, Charles ER (1990) Functions of the colour-opponent and broad-band channels of the visual system. Nature 343:68-70.

Sidman RL, Rakic P (1973) Neural migration with special reference to the developing human brain: a review. Brain Res 62:1-35.

Sireteanu R, Rieth C (1992) Texture segregation in infants and children. Behav Brain Res 49:133-139.

Tago H, Kimura H, Maeda T (1986) Visualization of detailed acelylcholinesterase fiber and neuron staining in rat brain by a sensitive histochemical procedure. J Histochem Cytochem 34:1431-1438.

Timney BN (1981) Development of binocular depth perception in kittens. Invest Ophthalmol Vis Sci 21:493-496.

Tootell RBH, Hamilton SL, Silverman MS, Switkes E (1988) Functional anatomy of macaque striate cortex. I. Ocular dominance, binocular interactions, and baseline conditions. J Neurosci 8:1500-1530

Tychsen L (1992a) Motion sensitivity and the origins of infantile strabismus. In: Infant vision: basic and clinical research (Simons K ed), in press. New York: Oxford UP.

Tychsen L (1992b) Binocular Vision. In: Adler's physiology of the cyc: clinical applications, 9th ed (Hart WM, ed), pp 773-853. St. Louis: Mosby.

Tychsen L, Burkhalter A (1992) Naturally-strabismic primate lacks intrinsic horizontal connections for binocular vision in striate cortex Soc Neurosci Abstr 18:1455.

Tychsen L, Lisberger SG (1986) Maldevelopment of visual motion processing in humans who had strabismus onset in infancy. J Neurosci 6:2495-2508

Van Sluyters RC, Atkinson J, Banks MS, Held RM, Hoffmann K-P, Shatz CS (1990) The development of vision and visual perception. In: Visual perception. The neurophysiological foundation (Spillmann L, Werner JS, eds), pp 349-379. New York: Academic.

Wattham-Bell J (1991) Development of motion-specific cortical responses in infancy. Vision Res 31:287-297.

Wattham-Bcll J (1992) The development of maximum displacement limits for discrimination of motion direction in infancy. Vision Res $32: 621-630$.

Wilson HR (1988) Development of spatiotemporal mechanisms in infant vision. Vision Res 28:611-628.

Worgötter F, Eysel UT (1991) Topographical aspects of intracortical excitation and inhibition contributing to orientation specificity in area 17 of the cat visual cortex. Eur J Neurosci 3:1232-1244.

Yoshioka T, Lund JS (1990) Substrates for interaction of visual channels within area V1 of monkey visual cortex. Soc Neurosci Abstr 16: 707. 